\title{
Facilely Synthesized Meso-Macroporous Polymer as Support of Poly(ethyleneimine) for Highly Efficient and Selective Capture of $\mathrm{CO}_{2}$
}

Fujian Liu, ${ }^{a, b}$ Kuan Huang, ${ }^{b}$ Chun-Jae Yoo, ${ }^{c}$ Claudia Okonkwo, ${ }^{c}$ Duan-Jian Tao, ${ }^{b}$ Christopher W. Jones, ${ }^{c}$ and Sheng Dai ${ }^{b, d} *$

${ }^{a}$ College of Chemistry \& Chemical Engineering, Shaoxing University, Shaoxing, Zhejiang 312000, China.

${ }^{b}$ Department of Chemistry, University of Tennessee, Knoxville, TN 37996, USA.

(Current address: Key Laboratory of Poyang Lake Environment and Resource Utilization of Ministry of Education, School of Resources Environmental and Chemical Engineering, Nanchang University, Nanchang 330031, China)

${ }^{c}$ School of Chemical \& Biomolecular Engineering, Georgia Institute of Technology, Atlanta, GA 30332, USA.

${ }^{d}$ Chemical Sciences Division, Oak Ridge National Laboratory, Oak Ridge, TN 37831, USA.

*Correspondingauthors: khuang8@utk.edu; dais@ornl.gov. 


\section{ABSTRACT}

Poly(ethyleneimine) (PEI) impregnated adsorbents are promising alternatives to amine-based liquid absorbents for post-combustion capture of $\mathrm{CO}_{2}$. A current challenge is to identify meso- and/or macroporous supports with large pore volumes that can be facilely synthesized from a cost-effective approach as supports for PEI. In this work, hierarchically nanoporous poly(divinylbenzene) (PDVB) is synthesized through a one-step polymerization of readily available divinylbenzene (DVB) under solvothermal conditions without use of any template or catalyst. The synthesized PDVB is found to have abundant meso-macropores, as well as a large pore volume. Subsequently, a series of PEI-impregnated PDVB sorbents is prepared and their performance for the selective adsorption of $\mathrm{CO}_{2}$ is investigated. The PEI-PDVB composites are found to exhibit promising $\mathrm{CO}_{2}$ capacities and exceptionally high $\mathrm{CO}_{2} / \mathrm{N}_{2}$ selectivities. The strength of $\mathrm{CO}_{2}$ adsorption is experimentally determined by direct calorimetric measurements. The PEI-PDVB composites show excellent stability under both dry and humidified sorption conditions during extended adsorption-desorption cycles. Based on the results obtained, these PEI-PDVB composites are identified as sorbents with significant potential for application in practical $\mathrm{CO}_{2}$ capture from industrial gas streams.

\section{KEYWORDS}

Porous Polymer; Poly(divinylbenzene); Poly(ethyleneimine); Physical Impregnation; $\mathrm{CO}_{2}$ Adsorption; Selectivity. 


\section{INTRODUCTION}

The constant increase in the $\mathrm{CO}_{2}$ concentration in the atmosphere over the past century is an issue of wide concern because it may cause various climatic and environmental problems, such as global warming and ocean acidification.[1] Emissions of $\mathrm{CO}_{2}$ mainly stem from industrial activity, which relies greatly on the use of fossil fuels. However, fossil fuels will still be the major source of energy for industrial activity in the near future, and eliminating $\mathrm{CO}_{2}$ from the tail gases of industrial processes is thus a direct solution to reducing $\mathrm{CO}_{2}$ emissions. For this purpose, wet amine-scrubbing technology was developed and has been widely employed for capturing $\mathrm{CO}_{2}$ from various gas streams industry.[2] It makes use of the chemical reactivity of amine compounds with $\mathrm{CO}_{2}$, which results in the formation of carbamate or bicarbonate, to realize the effective removal of $\mathrm{CO}_{2}$. However, the regeneration of amine-based absorbents is energy-intensive because of the high heat capacity of liquid aqueous solvents.[3] In addition, organic amines are highly volatile and corrosive; those characteristics contribute to a number of problems, for example, rapid consumption of absorbents and high operational costs for replacing corroded units.[3]

As substitutes for amine-based absorbents, various solid adsorbents-including porous silicas,[4] porous carbons,[5] zeolites,[6] metal-organic framework (MOFs)[7] and porous organic polymers (POPs)[8] - have been developed for $\mathrm{CO}_{2}$ adsorption. Compared with the amine-scrubbing process, the solid-adsorption process features lower energy consumption and negligible volatility and corrosivity,[9] making solid 
adsorbents promising candidates for $\mathrm{CO}_{2}$ capture. Among those solid adsorbents, POPs are particularly attractive because of their versatility in building blocks and synthetic routes, which makes it easy to tune their structure and porosity.[10-13] POPs have a low skeleton density because they are composed of only light elements (e.g., C, $\mathrm{H}, \mathrm{N}$ and $\mathrm{O}$ ).[14] The covalent structure of POPs endows them with high thermal stability.[15] Furthermore, most POPs show good water-tolerance,[16-18] unlike many MOFs,[19] which is crucial for their application in the post-combustion capture of $\mathrm{CO}_{2}$.

To enable them to compete with traditional amine-based absorbents, improvement of the $\mathrm{CO}_{2}$ capacity and $\mathrm{CO}_{2} / \mathrm{N}_{2}$ selectivity of pristine POPs under industrial conditions (e.g., elevated temperature and low partial pressure) is needed, because the inherent surface inertness of pristine POPs results in weak interactions between $\mathrm{CO}_{2}$ and pristine POPs. Inspired by the chemistry of the amine-scrubbing process, functionalizing the surface of nanoporous adsorbents with amine groups is a widely used strategy for enhancing the selective adsorption of $\mathrm{CO}_{2}$ on them.[9,20] For example, Zhou et al.[21] tethered polyamines to the benzene ring of PPN-6. The resultant PPN-6- $\mathrm{CH}_{2}$-DETA can adsorb $3.04 \mathrm{mmol} / \mathrm{g}$ of $\mathrm{CO}_{2}$ at $22^{\circ} \mathrm{C}$ and 0.15 bar, with a $\mathrm{CO}_{2} / \mathrm{N}_{2}$ selectivity of 442 . The same group[22] also developed a facile strategy to construct porous polymers with secondary amine groups embedded in the framework, using a nucleophilic substitution reaction between 2,4,6-tris(chloromethyl)mesitylene and ethylene diamine with triblock copolymer 
P123 as the template. As-prepared PPN-81 can adsorb $1.93 \mathrm{mmol} / \mathrm{g}$ of $\mathrm{CO}_{2}$ at $22^{\circ} \mathrm{C}$ and 1 bar, with a $\mathrm{CO}_{2} / \mathrm{N}_{2}$ selectivity of 4716 .

Although relatively stable amine-POP composites can be obtained through the chemical grafting of amine groups to the surface of POPs, the physical impregnation of amine compounds, especially poly(ethyleneimine) (PEI), into the inner pores of POPs represents a potentially more attractive method of preparing amine-POP composites.[20,23] The synthetic route of physical impregnation is very simple and easy for large-scale production. To our knowledge, the study of POPs as supports for PEI for $\mathrm{CO}_{2}$ adsorption is very limited[24-28], although many other porous materials have been extensively studied.[29-44] A representative work most recently published is from Suh et al.,[27] who reported the efficient and selective capture of $\mathrm{CO}_{2}$ by PEI-PAF-5 composites. A PEI-PAF-5 composite containing 40 wt. $\%$ of PEI can adsorb $2.66 \mathrm{mmol} / \mathrm{g}$ of $\mathrm{CO}_{2}$ at $25^{\circ} \mathrm{C}$ and 0.15 bar with a $\mathrm{CO}_{2} / \mathrm{N}_{2}$ selectivity of 1200 . Another study is from Lively et al.,[28] who used PIM-1 as a solution-processable PEI support for $\mathrm{CO}_{2}$ capture. The PEI-PIM-1 composite containing 21 wt.\% of PEI can adsorb $1.15 \mathrm{mmol} / \mathrm{g}$ of $\mathrm{CO}_{2}$ at $35^{\circ} \mathrm{C}$ from $10 \% \mathrm{CO}_{2}$ balanced in $\mathrm{N}_{2}$.

However, the synthesis of PAF-5 and PIM-1 is relatively complicated and requires expensive monomers and/or catalysts. Actually, most reported PEI supports also are uneconomical to synthesize, hindering their industrial application. For example, the mesopores in SBA-15 are created by employing large amounts of a high-cost template.[29] Moreover, the microporous structures of PAF-5 and PIM-1 are not ideally suitable for good dispersion of PEI because of the large molecular size of 
PEI. In addition, their relatively small pore volumes limit the amount of PEI that can be incorporated. As a consequence, a meso- and/or macroporous support with large pore volume that can be facilely synthesized via a cost-effective route is highly interesting for the impregnation of PEI. In this work, hierarchically nanoporous poly(divinylbenzene) (PDVB) was synthesized through the one-step polymerization of readily available divinylbenzene (DVB) under solvothermal conditions without use of any template and catalyst.[45,46] The resultant PDVB is found to have distinctive meso-macroporosity and a large pore volume. Considering the simple synthetic route and meso-macroporous structure of this PDVB, it is thought to be a promising PEI support for the selective capture of $\mathrm{CO}_{2}$. With this in mind, different amounts of PEI were incorporated into the inner pores of PDVB via a physical impregnation method, giving a series of composite adsorbents. The performance of PEI-PDVB composites for the selective capture of $\mathrm{CO}_{2}$ was investigated systematically.

\section{EXPERIMENTAL}

\subsection{Chemicals}

Divinylbenzene (DVB, technical grade, $80 \mathrm{wt} . \%$ ), azobisisobutyronitrile (AIBN, 98 wt.\%), poly(ethyleneimine) (PEI, branched type, average $M_{\mathrm{w}}=800$ by LS) and tetrahydrofuran (THF) were supplied by Sigma Aldrich Co. Ltd., USA. $\mathrm{CO}_{2}$ (research grade, $99.999 \mathrm{~mol} \%$ ), $\mathrm{CO}_{2}$ (research grade, $14.92 \mathrm{~mol} \%$ in $\mathrm{N}_{2}$ ), and $\mathrm{N}_{2}$ (ultrahigh purity grade, $99.999 \mathrm{~mol} \%$ ) were supplied by Airgas Co. Ltd., USA. All the reagents were used as received without further purification.

\subsection{Synthesis of Materials}


Poly(divinylbenzene) (PDVB) was synthesized by a solvothermal and template-free method.[45,46] First, $0.065 \mathrm{~g}$ of AIBN was dissolved in $25 \mathrm{~mL}$ of THF/water $(10 / 1 \mathrm{v} / \mathrm{v})$, and $3 \mathrm{~mL}$ of DVB was added to the mixture under vigorous stirring for $3 \mathrm{~h}$ at room temperature. The solution was then transferred into an autoclave and heated at $120^{\circ} \mathrm{C}$ for $24 \mathrm{~h}$. After the completion of the reaction, the solvent was evaporated at room temperature for $24 \mathrm{~h}$ and the product was dried under vacuum at $80^{\circ} \mathrm{C}$ for another $24 \mathrm{~h}$. PDVB was obtained as a white, powdery solid. PEI-loaded PDVB samples were prepared by physical impregnation: $1.0 \mathrm{~g}$ of PDVB was mixed with $10 \mathrm{~mL}$ of a methanolic solution of PEI (containing $0.5,1.0,1.5$, and $2.0 \mathrm{~g}$ of PEI, respectively) and stirred at room temperature for $24 \mathrm{~h}$. The methanol was then removed by rotary evaporation at $60^{\circ} \mathrm{C}$, followed by drying under vacuum at $80^{\circ} \mathrm{C}$ for $12 \mathrm{~h}$. According to the measured PEI loadings ( $x$, defined as the weight fraction of PEI in the composite), the final samples were denoted as $x$ PEI@PDVB.

\subsection{Characterization}

Before characterization, the powdery samples were pretreated at $110^{\circ} \mathrm{C}$ under flowing $\mathrm{N}_{2}$ for $2 \mathrm{~h}$ to remove adsorbed $\mathrm{CO}_{2}$ and other residual solvents (e.g., water and methanol). The $\mathrm{N}_{2}$ adsorption isotherms at $-196^{\circ} \mathrm{C}$ were measured on a Micromeritics Gemini 2390a system to determine the textural properties. The total surface area was calculated from the $\mathrm{N}_{2}$ adsorption isotherms using the BET equation in a relative pressure range of $0.05 \sim 0.30$. The total pore volume was determined from the amount of $\mathrm{N}_{2}$ adsorbed at a relative pressure of 0.97 . The micropore volume was calculated from the $\mathrm{N}_{2}$ adsorption isotherms using the carbon black STSA $t$-plot 
equation within a thickness range of $0.45 \sim 0.60 \mathrm{~nm}$. The pore size distribution was derived from the $\mathrm{N}_{2}$ adsorption isotherms using the BJH model. The PEI loading was measured by elemental analysis on an Elementarvario EL II analyzer. Fourier transform infrared (FTIR) spectra were acquired on an Excalibur Series instrument with a MVP-Pro ATR accessory. The thermal stability was evaluated by a Seiko 6300 thermogravimetric analyzer (TGA) under flowing $\mathrm{N}_{2}(150 \mathrm{~mL} / \mathrm{min})$ with a ramping rate of $10^{\circ} \mathrm{C} / \mathrm{min}$. Scanning electron microscope (SEM) images were collected on a Zeiss Auriga Crossbeam SEM at an acceleration voltage of $5 \mathrm{kV}$. Transmission electron microscope (TEM) images were collected on a Zeiss Libra200 TEM at an acceleration voltage of $200 \mathrm{kV}$.

\subsection{Gas Adsorption Measurements}

Before gas adsorption measurements, the powdery samples were pretreated at $110{ }^{\circ} \mathrm{C}$ under flowing $\mathrm{N}_{2}$ for $2 \mathrm{~h}$ to remove adsorbed $\mathrm{CO}_{2}$ and other residual solvents (e.g., water and methanol). The $\mathrm{CO}_{2}$ adsorption capacity at atmospheric pressure and recycling of $\mathrm{CO}_{2}$ adsorption under both dry and humidified conditions were measured gravimetrically on the same TGA instrument. Approximately $5 \mathrm{mg}$ of the sample was placed in a ceramic crucible and transferred to the TGA chamber; after the sample was stabilized at the target temperature $\left(25,50,75\right.$ or $\left.100^{\circ} \mathrm{C}\right)$ under flowing $\mathrm{N}_{2}(150$ $\mathrm{mL} / \mathrm{min}$ ) for $0.5 \mathrm{~h}$, the $\mathrm{N}_{2}$ flow was switched to a $\mathrm{CO}_{2}$ flow $\left(99.999 \%\right.$ or $14.7 \%$ in $\mathrm{N}_{2}$, $50 \mathrm{~mL} / \mathrm{min}$ ); subsequently, both the temperature and $\mathrm{CO}_{2}$ flow were maintained for 3 $\mathrm{h}$, and the weight gain during this period of time was taken as the $\mathrm{CO}_{2}$ adsorption capacity. For the cycling of $\mathrm{CO}_{2}$ adsorption under dry conditions, after the sample 
was stabilized at $25{ }^{\circ} \mathrm{C}$ under flowing $\mathrm{N}_{2}(150 \mathrm{~mL} / \mathrm{min})$ for $0.5 \mathrm{~h}$, the $\mathrm{N}_{2}$ flow was switched to a $\mathrm{CO}_{2}$ flow $(99.999 \%, 50 \mathrm{~mL} / \mathrm{min})$; both the temperature and $\mathrm{CO}_{2}$ flow were maintained for $3 \mathrm{~h}$; subsequently, the $\mathrm{CO}_{2}$ flow was switched back to the $\mathrm{N}_{2}$ flow and the temperature was increased to $75^{\circ} \mathrm{C}$; both the temperature and $\mathrm{N}_{2}$ flow were maintained for $2 \mathrm{~h}$; the sorbent cycling was performed 10 times. For the cycling of $\mathrm{CO}_{2}$ adsorption under humidified conditions, after the sample was stabilized at $75{ }^{\circ} \mathrm{C}$ under flowing $\mathrm{N}_{2}(150 \mathrm{~mL} / \mathrm{min})$ for $0.5 \mathrm{~h}$, the $\mathrm{N}_{2}$ flow was switched to a $\mathrm{CO}_{2}$ flow with a relative humidity of $10 \%$ at $75^{\circ} \mathrm{C}$; both the temperature and $\mathrm{CO}_{2}$ flow were maintained for $3 \mathrm{~h}$; subsequently, the $\mathrm{CO}_{2}$ flow was switched back to the $\mathrm{N}_{2}$ flow, and the $\mathrm{N}_{2}$ flow was maintained for $2 \mathrm{~h}$; the sorbent cycling was performed 10 times. Additionally, the $\mathrm{CO}_{2}$ and $\mathrm{N}_{2}$ adsorption isotherms at $25^{\circ} \mathrm{C}$ were measured volumetrically on a Micromeritics Gemini 2390t system to calculate the ideal selectivity of $\mathrm{CO}_{2} / \mathrm{N}_{2}$.

\subsection{Calorimetric Measurements}

The isosteric heats of $\mathrm{CO}_{2}$ adsorption at $30^{\circ} \mathrm{C}$ were measured using a customized Setaram Sensys Evo calorimeter, a conduction calorimeter which is also known as Tian-Calvet heat flux microcalorimeter. The detailed experimental procedure can be found in prior reports.[47,48] In brief, the sample was first pressed at 1000 psig and then crushed into pellets with particle size of $150 \sim 250 \mu \mathrm{m}$. Theoretically, the aggregation of samples for calorimetric measurements and $\mathrm{CO}_{2}$ adsorption measurements should be the same for rational comparison. However, our previous work[49] has systematically investigated the effect of pelletization on the physical 
and chemical properties of supported amine adsorbents, and found no change in chemical structure after pelletization at $1000 \mathrm{psig}$. Although the pelletized adsorbents had higher mass transfer resistance than powdery counterparts due to slight change in porosity, their equilibrium capacity are comparable. Since we mainly discussed the $\mathrm{CO}_{2}$ adsorption on the basis of pseudo-equilibrium state, it does not matter to use pelletized or powdery samples for measurements. Subsequently, $50 \mathrm{mg}$ of the pellets was loaded into one side of sample cell that has two prongs. Another side of the cell was left empty as a reference. This cell is connected to the dosing manifold and encased in an aluminum block that contains highly sensitive thermometers. The sample was pretreated at $110^{\circ} \mathrm{C}$ for $3 \mathrm{~h}$ under $15 \mathrm{~Pa}$ of vacuum, and then the temperature was cooled down to $30^{\circ} \mathrm{C}$. Two pressure transducers were connected to the reservoir and cell areas, which were maintained at $30^{\circ} \mathrm{C}$ with heating tape. The amount of adsorbed $\mathrm{CO}_{2}$ after dosing was calculated by mole balance using initial and final pressure values from the cell and reservoir sides. Heats of $\mathrm{CO}_{2}$ adsorption were simultaneously recorded while the dosed $\mathrm{CO}_{2}$ was adsorbed by the adsorbents.

\section{RESULTS AND DISCUSSION}

\subsection{Textural Properties}

It is well established that the textural properties of the support have a significant impact on the dispersion of PEI in the inner pores of the support.[29,38,50] Since the PEI typically used has a large molecular size $\left(M_{\mathrm{w}}=800\right)$, a support with large pores is considered to be a good choice for PEI impregnation. Figure 1 shows the $\mathrm{N}_{2}$ adsorption isotherms at $-196^{\circ} \mathrm{C}$ and the pore size distributions of the PDVB support 
and PEI-PDVB composites, and the calculated textural properties are summarized in Table 1. Notably, the PDVB support shows a type-IV isotherm with low $\mathrm{N}_{2}$ uptake at low relative pressure and high $\mathrm{N}_{2}$ uptake at high relative pressure. The $\mathrm{N}_{2}$ uptake displays a steep increase at a relative pressure of $0.8 \sim 0.975$. The pore size distribution of PDVB covers a wide range of $0 \sim 50 \mathrm{~nm}$, with considerable $\mathrm{dV} / \mathrm{d} \log (\mathrm{w})$ pore volume in the pore width range of $10 \sim 50 \mathrm{~nm}$, indicating that abundant meso-macropores are present in the PDVB support. As a result, PDVB is found to exhibit a large total pore volume $\left(2.05 \mathrm{~cm}^{3} / \mathrm{g}\right)$. The micropore volume $\left(0.09 \mathrm{~cm}^{3} / \mathrm{g}\right)$ accounts for only $4.4 \%$ of the total pore volume, implying that most inner pores of PDVB are likely accessible to PEI.

In light of the highly interesting meso-macroporous structure of PDVB, four PEI-PDVB composites with different PEI loadings were prepared in this work. The PEI loadings were calculated from the nitrogen contents determined by elemental analysis (see Table S1). The PEI loading ranges from 29 to $70 \mathrm{wt} . \%$, representing low to high occupancy of the inner pores. It can be seen from Figure 1 that the $\mathrm{N}_{2}$ uptake and $\mathrm{dV} / \mathrm{d} \log (\mathrm{w})$ pore volume decrease dramatically with the increase in PEI loading. Accordingly, the BET surface area and total pore volume also decrease dramatically with the increase in loading, as presented in Table 1. The PEI loading can reach as high as $70 \mathrm{wt} . \%$ in PEI-PDVB composites, corresponding to the PEI/PDVB mass ratio of 2.33, which approaches the theoretical value calculated from the total pore volume of PDVB (2.05). Therefore, the inner pores of PDVB are almost completely filled by PEI in the highest loading sample. This is attributed to the large pore widths 
of PDVB, which make the deep channels easily accessible to large PEI molecules. However, the highest PEI loading in PEI-PAF-5 composites reported in the literature was 40 wt.\%,[27] corresponding to a PEI/PAF-5 mass ratio of 0.80 , much lower than the theoretical value calculated from the total pore volume of PAF-5 (1.43). The small pore width of PAF-5 $(2.11 \mathrm{~nm})$ makes the deep channels easily blocked by aggregated PEI. Based on this comparison, it can be concluded that meso-macroporous PDVB has great potential as a PEI support.

Note that the units of $\mathrm{N}_{2}$ uptake and $\mathrm{dV} / \mathrm{d} \log (\mathrm{w})$ pore volume in Figure 1 are based on the mass of PEI-PDVB composites (i.e., $\mathrm{m}^{2} / \mathrm{g}$ composite and $\mathrm{cm}^{3} / \mathrm{g}$ composite). To clearly demonstrate the changes in the porosity of PDVB after PEI impregnation, those units were transformed to be based on the mass of PDVB (i.e., $\mathrm{m}^{2} / \mathrm{g}$ PDVB and $\mathrm{cm}^{3} / \mathrm{g}$ PDVB), as shown in Figure S1. It can be seen that when a small amount of PEI (29 wt.\%) is impregnated, the decrease in the $\mathrm{dV} / \mathrm{d} \log (\mathrm{w})$ pore volume over a small pore-width range $(0 \sim 10 \mathrm{~nm})$ is much more pronounced than the decrease over a large pore-width range $(10 \sim 50 \mathrm{~nm})$. As more and more PEI (42 70 wt.\%) is impregnated, the $\mathrm{dV} / \mathrm{d} \log (\mathrm{w})$ pore volume over a small pore-width range $(0 \sim 10 \mathrm{~nm})$ further decreases to negligible values, while the volume over a large pore-width range $(10 \sim 50 \mathrm{~nm})$ starts to decrease gradually. From this phenomenon, it is deduced that PEI fills the small pores first and then fills the large pores stepwise, indicating that PEI is well dispersed in the inner pores of PDVB.

\subsection{Morphology}


The porous structure and surface morphology of PDVB and PEI-PDVB composites were further examined by electron microscopy. Figure 2 shows the TEM images of PDVB and SEM images of PDVB and PEI-PDVB composites. The hierarchical meso-macroporosity of PDVB can be clearly observed from the TEM and SEM images, which is consistent with the results calculated from the $\mathrm{N}_{2}$ adsorption isotherms at $-196^{\circ} \mathrm{C}$. The porous structure of PDVB displays wormhole-like and disordered characteristics. The surface morphology of PEI-PDVB composites is somewhat similar to that of pristine PDVB, and obviously open pores can still be seen in the PEI-PDVB composites. Moreover, no stacking particles can be found in the SEM images of PEI-PDVB composites. These observations are consistent with the hypothesis that PEI resides in the inner pores of PDVB, not on the external surface.

\subsection{FTIR Characterization}

To ensure the presence of PEI in PEI-PDVB composites and probe the interaction of PEI with PDVB, the FTIR spectra of PEI, PDVB and PEI-PDVB composites were collected, as shown in Figure 3. The characteristic peaks of PEI can be clearly seen in PEI-PDVB composites. For example, the peak at $910 \mathrm{~cm}^{-1}$ is attributed to the out-of-plane deformation of $-\mathrm{NH}_{2}$, the peak at $1045 \mathrm{~cm}^{-1}$ is attributed to the stretching vibration of the $\mathrm{C}-\mathrm{N}$ bond, the peak at $1600 \mathrm{~cm}^{-1}$ is attributed to the deformation of the N-H bond, and the double peaks at around $3300 \mathrm{~cm}^{-1}$ are attributed to the symmetric and asymmetric stretching vibrations of the $\mathrm{N}-\mathrm{H}$ bond. The strength of these peaks increases with the increase in PEI loading. Furthermore, no blue shift or red shift of the characteristic peaks of PEI can be observed, implying 
that the interactions of PEI with PDVB are rather weak. This is reasonable, since there are only aromatic rings and alkyl chains in the skeleton of PDVB, neither of which can interact with PEI strongly.

\subsection{Thermal Stability}

The thermal stability of PEI-PDVB composites was examined by thermogravimetric analysis (TGA), as shown in Figure 4. From the TGA profiles, it can be seen that PEI-PDVB composites are stable up to $200^{\circ} \mathrm{C}$. The thermal stability of the PEI-PDVB composites is sufficient for them to be used in the post-combustion capture of $\mathrm{CO}_{2}$ from industrial streams.[51] Furthermore, there are two peaks in the derived TG (DTG) profiles of the PEI-PDVB composites, demonstrating bimodal behavior for the decomposition of the PEI-PDVB composites. The first DTG peak is centered at $390^{\circ} \mathrm{C}$, which is attributed to the volatilization and decomposition of PEI. The second DTG peak is centered at $460^{\circ} \mathrm{C}$, which is attributed to the decomposition of the PDVB network. It is interesting that the positions of the two peaks are the same as those appearing in the DTG profiles of pure PEI and pristine PDVB, further validating the rather weak interactions between PEI and PDVB.

\section{5 $\mathrm{CO}_{2}$ Capacities}

The adsorption capacities of the PDVB and PEI-PDVB composites using pure $\mathrm{CO}_{2}$ were determined by TGA. The $\mathrm{CO}_{2}$ adsorption profiles at different temperatures can be found in the Supplementary Material (Figures S2 S5). The $\mathrm{CO}_{2}$ capacities of the PEI-PDVB composites are much higher than those of pristine PDVB, and the difference is more pronounced at high temperatures. For example, the $\mathrm{CO}_{2}$ capacities 
of the PEI-PDVB composites at 25 and $75^{\circ} \mathrm{C}(2.08 \sim 3.70$ and $1.59 \sim 3.83 \mathrm{mmol} / \mathrm{g})$ are 4.6 8.2 and 9.4 22.5 times greater than those of PDVB (0.45 and $0.17 \mathrm{mmol} / \mathrm{g})$, respectively. The significantly enhanced $\mathrm{CO}_{2}$ adsorption on the PEI-PDVB composites is undoubtedly a result of the strong chemical reactivity of amine compounds with $\mathrm{CO}_{2}$, whereas pristine PDVB exhibits only very weak physical interactions with $\mathrm{CO}_{2}$ because of its surface inertness.

To demonstrate the structure-property relationship of the PEI-PDVB composites for $\mathrm{CO}_{2}$ adsorption, the $\mathrm{CO}_{2}$ capacities were plotted against the adsorption temperatures and PEI loadings in Figure 5. Figure 5A shows the variation of the $\mathrm{CO}_{2}$ capacity with the adsorption temperature, which is somewhat complicated. The negative effect of temperature on the $\mathrm{CO}_{2}$ capacity of pristine PDVB is not surprising because of the very weak physical interactions of $\mathrm{CO}_{2}$ with PDVB. However, temperature has two contradictory effects on the $\mathrm{CO}_{2}$ capacity of the PEI-PDVB composites: (1) $\mathrm{CO}_{2}$ adsorption on PEI-PDVB composites is a diffusion-controlled process, and increasing the temperature enhances $\mathrm{CO}_{2}$ diffusion into thick layers of PEI; (2) the reaction of $\mathrm{CO}_{2}$ with amine compounds is exothermic, and increasing the temperature weakens the interaction of $\mathrm{CO}_{2}$ with PEI. The first effect enhances $\mathrm{CO}_{2}$ adsorption and the second does not. For 0.29PEI@PDVB and 0.42PEI@PDVB, the PEI loadings are relatively low (29.0 wt.\% and 42.2 wt.\%), and the materials still have considerable BET surface areas $\left(227\right.$ and $\left.77 \mathrm{~m}^{2} / \mathrm{g}\right)$ and total pore volumes $(0.83$ and $0.45 \mathrm{~cm}^{3} / \mathrm{g}$ ). Additionally, the thickness of the PEI layers in the low PEI loading materials is relatively limited. Therefore, $\mathrm{CO}_{2}$ can easily diffuse into the PEI layers of 
these materials, and the $\mathrm{CO}_{2}$ adsorption on the two samples is thermodynamically controlled. As a result, the $\mathrm{CO}_{2}$ capacity of 0.29PEI@PDVB and 0.42PEI@PDVB decreases as temperature increases. In contrast, the PEI loadings for the 0.58PEI@PDVB and 0.70PEI@PDVB (57.7 wt.\% and 70.0 wt.\%) materials are markedly higher, and these samples have low BET surface areas $\left(38\right.$ and $\left.1 \mathrm{~m}^{2} / \mathrm{g}\right)$ and small total pore volumes $\left(0.32\right.$ and $\left.0.13 \mathrm{~cm}^{3} / \mathrm{g}\right)$. At $25 \sim 75^{\circ} \mathrm{C}, \mathrm{CO}_{2}$ can hardly diffuse into the deep layers of PEI, and the adsorption of $\mathrm{CO}_{2}$ on the two samples is increasingly kinetically controlled by $\mathrm{CO}_{2}$ diffusion through the PEI layers. Therefore, the $\mathrm{CO}_{2}$ capacities of 0.58PEI@PDVB and 0.70PEI@PDVB at $75^{\circ} \mathrm{C}(3.76$ and 3.83 $\mathrm{mmol} / \mathrm{g})$ were found to be even higher than those at $25^{\circ} \mathrm{C}(3.70$ and $3.17 \mathrm{mmol} / \mathrm{g})$. However, at $100^{\circ} \mathrm{C}$ diffusion is sufficiently fast and thermodynamics take over, and from that point, the adsorption of $\mathrm{CO}_{2}$ is no longer kinetically controlled. Hence, the $\mathrm{CO}_{2}$ capacities of 0.58PEI@PDVB and 0.70PEI@PDVB at $100^{\circ} \mathrm{C}(3.05$ and 3.58 $\mathrm{mmol} / \mathrm{g})$ are lower than those at $75^{\circ} \mathrm{C}(3.76$ and $3.83 \mathrm{mmol} / \mathrm{g})$.

Figure 5B shows the variation of $\mathrm{CO}_{2}$ capacity with PEI loading. Similar to adsorption temperature, PEI loading also has two contrary effects on $\mathrm{CO}_{2}$ capacity: (1) increasing the PEI loading provides more active sites for the reaction with $\mathrm{CO}_{2}$ and enhances the interaction of $\mathrm{CO}_{2}$ with adsorbents; (2) increasing the PEI loading decreases the porosity of PEI-PDVB composites, thickens the PEI layers and hinders the diffusion of $\mathrm{CO}_{2}$ into the depth of the PEI. In the relatively low PEI loading range of $0 \sim 57.7$ wt.\%, the first effect dominates $\mathrm{CO}_{2}$ adsorption. Therefore, the $\mathrm{CO}_{2}$ capacity increases with as increase in PEI loading in this range. However, when the 
PEI loading is further increased to as high as $70.0 \mathrm{wt} . \%$, two different trends for the variation in $\mathrm{CO}_{2}$ capacity with PEI loading are observed. At 75 and $100^{\circ} \mathrm{C}$, the first effect still dominates the adsorption of $\mathrm{CO}_{2}$ because of the elimination of the diffusion barrier. Therefore, the $\mathrm{CO}_{2}$ capacities of 0.70PEI@PDVB are higher than those of 0.58PEI@PDVB at the two temperatures. In contrast, the second effect dominates the adsorption of $\mathrm{CO}_{2}$ at 25 and $50^{\circ} \mathrm{C}$. As a result, the $\mathrm{CO}_{2}$ capacities of $0.70 \mathrm{PEI} @$ PDVB are even lower than those of $0.58 \mathrm{PEI} @ \mathrm{PDVB}$ at the two temperatures. This kind of trend relating the $\mathrm{CO}_{2}$ capacity and PEI loading has also been observed by others in the literature.[32,52]

Based on $\mathrm{CO}_{2}$ capacities and PEI loadings, the amine efficiencies (defined as the ratio of adsorbed $\mathrm{CO}_{2}$ /amine group) of the PEI-PDVB composites were calculated, and the results are presented in Figure 6. Since the ratio of primary/secondary/tertiary amine groups in branched PEI is $0.44: 0.33: 0.23,[53]$ the maximum amine efficiency is 0.38 , assuming that tertiary amine is unable to chemically react with $\mathrm{CO}_{2}$ and the formation of ammonium carbamate consumes two primary/secondary amine groups. Owing to the good dispersion of PEI in the inner pores of PDVB, the amine efficiency of the PEI-PDVB composites can reach as high as $0.18 \sim 0.29$ at $25^{\circ} \mathrm{C}$ and $0.22 \sim 0.27$ at $75^{\circ} \mathrm{C}$, implying an efficient utilization of PEI for $\mathrm{CO}_{2}$ capture.

Considering the low $\mathrm{CO}_{2}$ concentrations in industrial streams, the adsorption capacities of dilute $\mathrm{CO}_{2}$ (typically $15 \mathrm{v} / \mathrm{v} \%$ ) are more meaningful for practical assessments. Therefore, the adsorption capacities using $15 \% \mathrm{CO}_{2}$ on PDVB and the PEI-PDVB composites were also determined by TGA. The $\mathrm{CO}_{2}$ adsorption profiles 
can be found in the Supplementary Material (Figures S6 S9). The adsorption capacities of $15 \% \mathrm{CO}_{2}$ on PEI-PDVB composites at 25 and $75^{\circ} \mathrm{C}$ are $1.71 \sim 3.04$ and 1.13 2.93 mmol/g, respectively. However, PDVB can adsorb only traces of $\mathrm{CO}_{2}$ under the same conditions. The adsorption capacities using $15 \% \mathrm{CO}_{2}$ on the PEI-PDVB composites are comparable to or even higher than those on many other PEI-impregnated adsorbents, for example, 0.40PEI@PAF-5 (2.45 mmol/g, 15\% CO at $\left.40^{\circ} \mathrm{C}\right),[27] \quad 0.25 \mathrm{PEI} @ \mathrm{PIM}-1 \quad\left(0.97 \mathrm{mmol} / \mathrm{g}, \quad 10 \% \quad \mathrm{CO}_{2} \quad\right.$ at $\left.\quad 35^{\circ} \mathrm{C}\right),[28]$ 0.31PEI@SBA-15 (0.65 mmol/g, 10\% $\mathrm{CO}_{2}$ at 35²),[31] 0.33PEI@Zr7-SBA-15 $\left(1.56 \mathrm{mmol} / \mathrm{g}, 10 \% \mathrm{CO}_{2}\right.$ at $\left.25^{\circ} \mathrm{C}\right),[31] 0.40 \mathrm{PEI} @ \mathrm{SBA}-15\left(1.61 \mathrm{mmol} / \mathrm{g}, 10 \% \mathrm{CO}_{2}\right.$ at

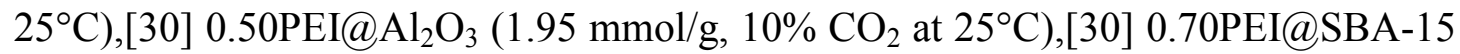
(2.00 mmol/g, 1 bar of pure $\mathrm{CO}_{2}$ at $\left.45^{\circ} \mathrm{C}\right)$,[23] 0.30PEI@PME $(2.04 \mathrm{mmol} / \mathrm{g}, 10 \%$ $\mathrm{CO}_{2}$ at $\left.25^{\circ} \mathrm{C}\right)[43]$ and 0.40PEI@silica $\left(2.16 \mathrm{mmol} / \mathrm{g}, 15 \% \mathrm{CO}_{2}\right.$ at $\left.70^{\circ} \mathrm{C}\right)$.[44] This comparison demonstrates the capability of PEI-PDVB composites to capture $\mathrm{CO}_{2}$ at high efficiencies.

In Figure 7, the adsorption capacities using $15 \% \mathrm{CO}_{2}$ were plotted against the adsorption temperatures and PEI loadings. Using $15 \% \mathrm{CO}_{2}$, the variations in the adsorption capacity with temperature and PEI loading also suggest contributions of kinetic and thermodynamic factors, which are similar to those demonstrated in Figure 5. Based on the adsorption capacities using $15 \% \mathrm{CO}_{2}$ at various PEI loadings, the amine efficiencies of the PEI-PDVB composites for the adsorption of dilute $\mathrm{CO}_{2}$ were also calculated, and the results are presented in Figure 8. The amine efficiency of the PEI-PDVB composites for the adsorption of $15 \% \mathrm{CO}_{2}$ can reach as high as $0.13 \sim 0.27$ 
at $25^{\circ} \mathrm{C}$ and $0.17 \sim 0.22$ at $75^{\circ} \mathrm{C}$. The amine efficiencies of PEI-PDVB composites for the adsorption of dilute $\mathrm{CO}_{2}$ are comparable to or even higher than those of many other PEI-impregnated adsorbents, for example, 0.40PEI@PAF-5 $\left(0.25,15 \% \mathrm{CO}_{2}\right.$ at 40 $\mathrm{C}),[27]$ 0.25PEI@PIM-1 (0.16, 10\% $\mathrm{CO}_{2}$ at 35 $\left.{ }^{\circ} \mathrm{C}\right),[28]$ 0.31PEI@SBA-15 (0.09, $10 \% \quad \mathrm{CO}_{2}$ at $\left.35^{\circ} \mathrm{C}\right),[31] \quad 0.33 \mathrm{PEI} @ \mathrm{Zr} 7-\mathrm{SBA}-15\left(0.19, \quad 10 \% \quad \mathrm{CO}_{2}\right.$ at $\left.25^{\circ} \mathrm{C}\right),[31]$ 0.40PEI@SBA-15 $\left(0.16,10 \% \mathrm{CO}_{2}\right.$ at 25 $\left.{ }^{\circ} \mathrm{C}\right),[30]$ and 0.50PEI@ $\mathrm{Al}_{2} \mathrm{O}_{3}(0.16,10 \%$ $\mathrm{CO}_{2}$ at $25^{\circ} \mathrm{C}$ ).[30] implying the efficient utilization of PEI for the capture of dilute $\mathrm{CO}_{2}$ by PEI-PDVB composites.

It should be noted that a significant drawback associated with PEI-PDVB composites is the slow kinetics, which should arise from the blocking of diffusion channels and significant increase in the viscosity of impregnated PEI after complexed with $\mathrm{CO}_{2}$. As shown in Figures $\mathrm{S} 2 \sim \mathrm{S} 9$, the adsorption of $\mathrm{CO}_{2}$ on PEI-PDVB composites still does not reach equilibrium even at $180 \mathrm{~min}$, therefore, the $\mathrm{CO}_{2}$ capacities mentioned above are pseudo-equilibrium capacities. Furthermore, the rate of $\mathrm{CO}_{2}$ adsorption decreases with the increase of PEI loading, which is similar to the variation trend of porosity with PEI loading (see Table 1). These observations are consistent with the adsorption of $\mathrm{CO}_{2}$ on most other PEI-impregnated adsorbents.[24-44]

\section{6 $\mathrm{CO}_{2} / \mathrm{N}_{2}$ Selectivities}

In addition to $\mathrm{CO}_{2}$ capacity, $\mathrm{CO}_{2} / \mathrm{N}_{2}$ selectivity is also an important factor that should be taken into account in evaluating the performance of solid adsorbents for $\mathrm{CO}_{2}$ capture. Since the adsorption of $\mathrm{N}_{2}$ on PDVB and the PEI-PDVB composites is 
hardly detectable by TGA, the $\mathrm{CO}_{2}$ and $\mathrm{N}_{2}$ adsorption isotherms at $25^{\circ} \mathrm{C}$ for PDVB and the PEI-PDVB composites were measured by the volumetric method to calculate the ideal adsorption solution theory (IAST)[54] selectivity of $\mathrm{CO}_{2} / \mathrm{N}_{2}(0.15 / 0.85)$ at 1 bar (see Figure 9). The $\mathrm{CO}_{2}$ capacities at 1 and 0.15 bar determined by the volumetric method are similar to those determined by the TGA method, validating the accuracy of the data reported in this work. The $\mathrm{CO}_{2}$ adsorption isotherm of PDVB displays a typical physical profile, with the $\mathrm{CO}_{2}$ capacity increasing almost linearly with the $\mathrm{CO}_{2}$ pressure. This is consistent with the surface inertness of PDVB, which results in weak interactions of $\mathrm{CO}_{2}$ with PDVB. In contrast, the $\mathrm{CO}_{2}$ adsorption isotherms of the PEI-PDVB composites display typical chemical profiles, with the $\mathrm{CO}_{2}$ capacity increasing significantly with the $\mathrm{CO}_{2}$ pressure in the low-pressure range. However, the increasing trend gradually fades in the high-pressure range. This is consistent with the strong chemical reactivity of amine compounds with $\mathrm{CO}_{2}$. Moreover, the $\mathrm{N}_{2}$ adsorption isotherms of PDVB and the PEI-PDVB composites display typical physical profiles, with the $\mathrm{N}_{2}$ capacity increasing almost linearly with the $\mathrm{N}_{2}$ pressure. This is within expectations, considering the inertness of $\mathrm{N}_{2}$. Significantly, the $\mathrm{N}_{2}$ capacities of PEI-PDVB composites are 2 3 magnitudes lower than their $\mathrm{CO}_{2}$ capacities.

The IAST selectivity of $\mathrm{CO}_{2} / \mathrm{N}_{2}$ can be calculated by the equation $S=\left(q_{1} / p_{1}\right) /\left(q_{2} / p_{2}\right)$, where $q_{1}$ is the capacity of $\mathrm{CO}_{2}$ at the partial pressure of $p_{1}$, and $q_{2}$ is the capacity of $\mathrm{N}_{2}$ at the partial pressure of $p_{2}$. For the calculation of $\mathrm{CO}_{2} / \mathrm{N}_{2}$ selectivity in full $\mathrm{CO}_{2}$ concentration range $(0 \sim 1)$, the $\mathrm{CO}_{2}$ and $\mathrm{N}_{2}$ adsorption 
isotherms should be fitted with an adsorption model, for example dual-site Langmuir model or dual-site Langmuir-Freundlich model. However, only the single point $\mathrm{CO}_{2} / \mathrm{N}_{2}$ selectivity $\left(\mathrm{CO}_{2}: \mathrm{N}_{2}=0.15: 0.85\right.$ at 1 bar $)$ was calculated in this work, where the $\mathrm{CO}_{2}$ concentration is typical for flue gas. The capacity of $\mathrm{CO}_{2}$ at 0.15 bar and the capacity of $\mathrm{N}_{2}$ at 0.85 bar could be directly read from the isotherms, therefore, the calculated $\mathrm{CO}_{2} / \mathrm{N}_{2}$ selectivity is independent on the adsorption model applied. Even though, it should be noted that the calculated $\mathrm{CO}_{2} / \mathrm{N}_{2}$ selectivity is very sensitive to the accuracy of $\mathrm{N}_{2}$ capacity, since the $\mathrm{N}_{2}$ uptake was very low at the pressure range of testing ( $0 \sim 1$ bar). According to the calculated IAST $\mathrm{CO}_{2} / \mathrm{N}_{2}$ selectivities, PDVB has poor capability for the selective capture of $\mathrm{CO}_{2}$, with an IAST $\mathrm{CO}_{2} / \mathrm{N}_{2}$ selectivity of 19. However, impregnating PEI into the inner pores of PDVB not only enhances $\mathrm{CO}_{2}$ adsorption but also reduces $\mathrm{N}_{2}$ adsorption for he composite materials, thus providing exceptionally high IAST $\mathrm{CO}_{2} / \mathrm{N}_{2}$ selectivities of $721 \sim 3274$. Obviously, the IAST $\mathrm{CO}_{2} / \mathrm{N}_{2}$ selectivity of the PEI-PDVB composites increased as the PEI loading increased, and 0.70PEI@PDVB was found to exhibit the highest IAST $\mathrm{CO}_{2} / \mathrm{N}_{2}$ selectivity, 3274, among the four PEI-PDVB composites prepared in this work. This value is also higher than many other PEI-impregnated adsorbents, 0.40PEI@PAF-5 (1200),[27] 0.56PEI@MIL-101 (730),[33] and 0.50PEI@MIL-101(Cr) (1030),[36] demonstrating the capability of the PEI-PDVB composites for highly selective $\mathrm{CO}_{2}$ capture.

\subsection{Heats of Adsorption}


The heat of $\mathrm{CO}_{2}$ adsorption is an important parameter that reflects the strength of interaction between $\mathrm{CO}_{2}$ and adsorbent, and can be used for the preliminary evaluation of the energy penalty for the desorption of $\mathrm{CO}_{2}$. The Clausius-Clapeyron equation is a widely used tool for the calculation of isosteric heats of $\mathrm{CO}_{2}$ adsorption on porous materials from isotherm data obtained at multiple temperatures.[22,35] However, the Clausius-Clapeyron equation is not a good choice for the calculation of isosteric heats of $\mathrm{CO}_{2}$ adsorption on PEI-impregnated adsorbents, because the adsorption of $\mathrm{CO}_{2}$ on PEI-impregnated adsorbents can be a diffusion-controlled process, and the observed variation trend between $\mathrm{CO}_{2}$ pressure and temperature at a specific $\mathrm{CO}_{2}$ uptake may be flawed. To quantitatively and directly assess the interaction of $\mathrm{CO}_{2}$ with the PEI-PDVB composites, the isosteric heats of $\mathrm{CO}_{2}$ adsorption on the PEI-PDVB composites were experimentally measured as a function of $\mathrm{CO}_{2}$ uptake at $30^{\circ} \mathrm{C}$ by calorimetry, with the results shown in Figure 10 . Since $\mathrm{CO}_{2}$ is preferably bonded to stronger sites, the $\mathrm{CO}_{2}$ adsorption heat displays a typical decreasing trend with the $\mathrm{CO}_{2}$ uptake. The initial $\mathrm{CO}_{2}$ adsorption heats of the four PEI-PDVB composites at a low $\mathrm{CO}_{2}$ uptake of $\sim 0.1 \mathrm{mmol} / \mathrm{g}$ are $57 \sim 87 \mathrm{~kJ} / \mathrm{mol}$, corresponding the chemical reaction of $\mathrm{CO}_{2}$ with PEI. Generally, the initial $\mathrm{CO}_{2}$ adsorption heat increases with an increase of PEI loading, which can be ascribed to the increase of amine density.[48] As the $\mathrm{CO}_{2}$ uptake increases to $\sim 2 \mathrm{mmol} / \mathrm{g}$, the difference in $\mathrm{CO}_{2}$ adsorption heats of the four PEI-PDVB composites disminishes and the $\mathrm{CO}_{2}$ adsorption heat decreases to $20 \sim 30 \mathrm{~kJ} / \mathrm{mol}$. At this stage, the accessible 
chemical sites are saturated and the adsorption of $\mathrm{CO}_{2}$ is dominated by physical adsorption on the surface of the PEI-PDVB composites.

\subsection{Sorbent Cycling}

The stability of the PEI-PDVB composites for $\mathrm{CO}_{2}$ adsorption under dry conditions was tested by applying a combination of temperature swing and concentration swing cycling, and the results are shown in Figure 11. The adsorbed $\mathrm{CO}_{2}$ can be totally released under an $\mathrm{N}_{2}$ purge for 120 min at $75^{\circ} \mathrm{C}$, indicating the easy desorption of $\mathrm{CO}_{2}$ from the PEI-PDVB composites. A slight decrease in the baselines of the TGA profiles suggests the minor loss of PEI during cycling. However, many other reports did not investigate the possibility of regenerating their adsorbents at a relatively low temperature of $75^{\circ} \mathrm{C}$, for example PEI-G-silica $\left(120^{\circ} \mathrm{C}\right),[35]$ PEI-Al ${ }_{2} \mathrm{O}_{3}\left(110^{\circ} \mathrm{C}\right),[30]$ PEI-SBA-15 $\left(110^{\circ} \mathrm{C}\right),[31]$ PEI-Zr7-SBA-15 (110 $\left.{ }^{\circ} \mathrm{C}\right),[31]$ PEI-MIL-101 $\left(110^{\circ} \mathrm{C}\right),[33]$ PEI-MIL-101(Cr) $\left(110^{\circ} \mathrm{C}\right),[36]$ PEI-silica $\left(120^{\circ} \mathrm{C}\right)[39]$ and PEI-MDCM $\left(100^{\circ} \mathrm{C}\right)$.[38] Maybe those PEI-impregnated adsorbents can also be recycled under similar conditions. Even though, the easy desorption of $\mathrm{CO}_{2}$ for the PEI-PVDB composites demonstrated here clearly shows the easy cyclability of these new composite materials. As evidenced by the FTIR spectra and TGA results, the interactions of PEI with PDVB are rather weak, and this may offer good PEI mobility that allows for straightforward cycling. Considering the inert surface of PDVB, the main possible interaction of PEI with PDVB is a N-H--- $\pi$ interaction, the strength of which is located in the range of the van der Waals interactions. However, many other supports (e.g., SBA-15 and $\mathrm{Al}_{2} \mathrm{O}_{3}$ ) have abundant hydroxyl groups or Lewis acidic 
sites,[20] which can interact with the amine group in PEI strongly through a complex hydrogen bonding network or Lewis acid-base interactions, thus constraining the mobility of PEI. Furthermore, the $\mathrm{CO}_{2}$ capacities of the PEI-PDVB composites remain almost unchanged (the loss in $\mathrm{CO}_{2}$ capacities is less than 5\%) even after 10 cycles of adsorption/desorption. This can be explained by the relatively low temperature required for $\mathrm{CO}_{2}$ desorption, i.e., $75^{\circ} \mathrm{C}$. At such a temperature, the volatilization and degradation of PEI can be more efficiently avoided than when cycling at higher temperatures. In previous work, it has been elucidated that a high desorption temperature (e.g., $110^{\circ} \mathrm{C}$ ) is likely to induce the transformation of carbamate to urea under concentrated $\mathrm{CO}_{2}$ conditions,[55] which can be a major cause of the capacity loss during the regeneration of PEI-impregnated adsorbents. For example, the $\mathrm{CO}_{2}$ capacity of a PEI-SBA-15 composite decreased by $34 \%$ after four cycles if the desorption was performed at $110^{\circ} \mathrm{C}$ for $3 \mathrm{~h},[31]$ indicating that a conventional PEI/SBA-15 composite can have limited stability during higher temperature regeneration. In contrast, the PEI-PDVB composites prepared in this work demonstrate comparably high stability for $\mathrm{CO}_{2}$ capture.

Considering the inevitable presence of steam in industrial streams, it is more meaningful to investigate the recyclability of PEI-PDVB composites for $\mathrm{CO}_{2}$ adsorption under humidified conditions. Therefore, 0.58PEI@PDVB was selected as a representative material for such testing, where it was evaluated in 10 consecutive concentration swing cycles, with result shown in Figure 12. The results clearly demonstrate that 0.58PEI@PDVB exhibits excellent steam-stability during $\mathrm{CO}_{2}$ 
adsorption-desorption cycles under conditions with low water activity, with the uptake of humidified $\mathrm{CO}_{2}$ remaining almost unchanged after 10 cycles. The observed stability of 0.58PEI@PDVB in this modestly humid stream might be attributed to the super hydrophobic and water-tolerant nature of PDVB, $[45,46]$ which can preserve the porous structure of PDVB well. However, many other supports such as SBA-15 are vulnerable to steam-induced structural degradation under humidified conditions, which results the significant losses of $\mathrm{CO}_{2}$ capacity after recycling.[30,56] This comparison further supports the potential of PDVB as a useful support for PEI for $\mathrm{CO}_{2}$ adsorption applications.

It should be noted that $\mathrm{N}_{2}$ can not be used as the regenerant in real process for capturing $\mathrm{CO}_{2}$ from flue gas, since pure $\mathrm{CO}_{2}$ can not be obtained with $\mathrm{N}_{2}$ purge. However, concentration swing with $\mathrm{N}_{2}$ purge is widely used and accepted in the preliminary investigation of the long-term recyclability of PEI-impregnated adsorbents.[24-44] In this work, we were aiming to investigate the possibility of using PEI-PDVB composites as recyclable adsorbents for $\mathrm{CO}_{2}$ capture. It was found that no matter for the capture of dry $\mathrm{CO}_{2}$ or humidified $\mathrm{CO}_{2}$, PEI-PDVB composites can be facilely regenerated with $\mathrm{N}_{2}$ purge at $75^{\circ} \mathrm{C}$ and maintains the capacity of $\mathrm{CO}_{2}$ very well throughout consecutive cycles. As a preliminary work, we were not aiming to find a way to collect $\mathrm{CO}_{2}$ as a pure product. To obtain $\mathrm{CO}_{2}$ with high purity, steam regeneration is required. Steam regeneration is a technology recently developed for the effective recycling of $\mathrm{CO}_{2}$ adsorbents.[57-60] Steam with high temperature is a waste source of heat, and widely available in power plants. It provides the thermal 
driving force along with the concentration gradient for $\mathrm{CO}_{2}$ desorption. After condensing out the moisture and compressing $\mathrm{CO}_{2}$, concentrated $\mathrm{CO}_{2}$ product can be obtained. This technology was traditionally used for volatile organic compound separation,[61] but only a few studies have focused on its application in $\mathrm{CO}_{2}$ capture. Therefore, investigating the stability of PEI-PDVB composites after several cycles of $\mathrm{CO}_{2}$ adsorption and steam regeneration is very meaningful, and this will be the task of our future work.

\section{CONCLUSIONS}

A porous polymer, poly(divinylbenzene) (PDVB), was synthesized through the solvothermal polymerization of readily available divinylbenzene (DVB) under template-free and catalyst-free conditions. The synthesized PDVB is found to be a highly effective support for poly(ethyleneimine) (PEI) owing to its abundant meso-macropores and large pore volume, which enables the good dispersion of PEI in the inner pores of PDVB. The $\mathrm{CO}_{2}$ and $\mathrm{N}_{2}$ adsorption experiments demonstrate that PEI-PDVB composites exhibit fascinating performance for the selective capture of $\mathrm{CO}_{2}$. The adsorption capacity of $\mathrm{CO}_{2}$ and IAST selectivity of $\mathrm{CO}_{2} / \mathrm{N}_{2}$ on PEI-PDVB composites are comparable or superior to those of many other reported PEI-impregnated adsorbents. With the assistance of calorimetric method, the strength of interaction between $\mathrm{CO}_{2}$ and PEI-PDVB composites was quantitatively disclosed to provide a better understand about the behavior of $\mathrm{CO}_{2}$ adsorption on PEI-PDVB composites. The inert surface of PDVB results in the weak interaction of PEI with PDVB, contributing to the good mobility of impregnated PEI and the easy desorption 
of $\mathrm{CO}_{2}$ from PEI-PDVB composites. Furthermore, PEI-PDVB composites display high stability in $\mathrm{CO}_{2}$ adsorption/desorption cycles under both dry and humidified conditions. All these features suggest that PEI-PDVB composites are a class of promising materials with potential application in the post-combustion capture of $\mathrm{CO}_{2}$. Future work will focus on the stability of PEI-PDVB composites in steam regeneration, which is a promising technology to obtain $\mathrm{CO}_{2}$ product with high purity.

\section{ACKNOWLEDGMENTS}

This work was supported as part of the Center for Understanding and Control of Acid Gas-Induced Evolution of Materials for Energy (UNCAGE-ME), an Energy Frontier Research Center funded by the US Department of Energy, Office of Science, Office of Basic Energy Sciences, under Award No. DE-SC0012577.

\section{NOTES}

The authors declare no competing financial interest.

\section{REFERENCES}

[1] J.D. Figueroa, T. Fout, S. Plasynski, H. McIlvried, R.D. Srivastava, Advances in $\mathrm{CO}_{2}$ capture technology-The U.S. Department of Energy's Carbon Sequestration Program, Int. J. Greenh. Gas Con. 2 (2008) 9-20.

[2] G.T. Rochelle, Amine scrubbing for $\mathrm{CO}_{2}$ capture, Science 325 (2009) 1652-1654.

[3] A.B. Rao, E.S. Rubin, A technical, economic, and environmental assessment of amine-based $\mathrm{CO}_{2}$ capture technology for power plant greenhouse gas control, Environ. Sci. Technol. 36 (2002) 4467-4475. 
[4] Y. Belmabkhout, R. Serna-Guerrero, A. Sayari, Adsorption of $\mathrm{CO}_{2}$ from dry gases on MCM-41 silica at ambient temperature and high pressure. 1: Pure $\mathrm{CO}_{2}$ adsorption, Chem. Eng. Sci. 64 (2009) 3721-3728.

[5] A.H. Lu, G.P. Hao, X. Q. Zhang, Porous carbons for carbon dioxide capture, in: A.H. Lu, S. Dai (Eds.), Porous Materials for Carbon Dioxide Capture, Springer-Verlag, Berlin, 2014, pp. 15-77.

[6] M.R. Hudson, W.L. Queen, J.A. Mason, D.W. Fickel, R.F. Lobo, C.M. Brown, Unconventional, highly selective $\mathrm{CO}_{2}$ adsorption in zeolite SSZ-13, J. Am. Chem. Soc. 134 (2012) 1970-1973.

[7] J. Liu, P.K. Thallapally, B.P. McGrail, D.R. Brown, J. Liu, Progress in adsorption-based $\mathrm{CO}_{2}$ capture by metal-organic frameworks, Chem. Soc. Rev. 41 (2012) 2308-2322.

[8] R. Dawson, E. Stöckel, J.R. Holst, D. J. Adams, A.I. Cooper, Microporous organic polymers for carbon dioxide capture, Energy Environ. Sci. 4 (2011) 4239-4245.

[9] S. Choi, J.H. Drese, C.W. Jones, Adsorbent materials for carbon dioxide capture from large anthropogenic point sources, ChemSusChem 2 (2009) 796-854.

[10]Q.Q. Dang, Y.F. Zhan, X.M. Wang, X.M. Zhang, Heptazine-based porous framework for selective $\mathrm{CO}_{2}$ sorption and organocatalytic performances, ACS Appl. Mater. Interfaces 7 (2015) 28452-28458. 
[11] Y. Luo, B. Li, W. Wang, K. Wu, B. Tan, Hypercrosslinked aromatic heterocyclic microporous polymers: a new class of highly selective $\mathrm{CO}_{2}$ capturing materials, Adv. Mater. 24 (2012) 5703-5707.

[12]H. Gao, L. Ding, W. Li, G. Ma, H. Bai, L. Li, Hyper-cross-linked organic microporous polymers based on alternating copolymerization of bismaleimide, ACS Macro. Lett. 5 (2016) 377-381.

[13] V.M. Suresh, S. Bonakala, H.S. Atreya, S. Balasubramanian, T.K. Maji, Amide functionalized microporous organic polymer (Am-MOP) for selective $\mathrm{CO}_{2}$ sorption and catalysis, ACS Appl. Mater. Interfaces 6 (2014) 4630-4637.

[14]M.G. Rabbani, H.M. El-Kaderi, Synthesis and characterization of porous benzimidazole-linked polymers and their performance in small gas storage and selective uptake, Chem. Mater. 24 (2012) 1511-1517.

[15]S.Y. Ding, W. Wang, Covalent organic frameworks (COFs): from design to applications, Chem. Soc. Rev. 42 (2013) 548-568.

[16]H.A. Patel, F. Karadas, J. Byun, J. Park, E. Deniz, A. Canlier, Y. Jung, M. Atilhan, C.T. Yavuz, Highly stable nanoporous sulfur-bridged covalent organic polymers for carbon dioxide removal, Adv. Funct. Mater. 23 (2013) 2270-2276.

[17]D. Yuan, W. Lu, D. Zhao, H.C. Zhou, Highly stable porous polymer networks with exceptionally high gas-uptake capacities, Adv. Mater. 23 (2011) 3723-3725.

[18]C. Xu, E. Dinka, N. Hedin, Hydrophobic porous polyketimines for the capture of $\mathrm{CO}_{2}$, ChemPlusChem 81 (2016) 58-63. 
[19] N.C. Burtch, H. Jasuja, K.S. Walton, Water stability and adsorption in metal-organic frameworks, Chem. Rev. 114 (2014) 10575-10612.

[20]S.A. Didas, S. Choi, W. Chaikittisilp, C.W. Jones, Amine-oxide hybrid materials for $\mathrm{CO}_{2}$ capture from ambient air, Acc. Chem. Res. 48 (2015) 2680-2687.

[21]W. Lu, J.P. Sculley, D. Yuan, R. Krishna, Z. Wei, H.C. Zhou, Polyamine-tethered porous polymer networks for carbon dioxide capture from flue gas, Angew. Chem. Int. Ed. 51 (2012) 7480-7484.

[22]L.B. Sun, A.G. Li, X.D. Liu, X.Q. Liu, D. Feng, W. Lu, D. Yuan, H.C Zhou, Facile fabrication of cost-effective porous polymer networks for highly selective $\mathrm{CO}_{2}$ capture, J. Mater. Chem. A 3 (2015) 3252-3256.

[23]R. Sanz, G. Calleja, A. Arencibia, E.S. Sanz-Perez, CO2 adsorption on branched polyethyleneimine-impregnated mesoporous silica SBA-15, Appl. Surf. Sci. 256 (2010) 5323-5328.

[24] S. Lee, T.P. Filburn, M. Gray, J.W. Park, H.J. Song, Screening test of solid amine sorbents for $\mathrm{CO}_{2}$ capture, Ind. Eng. Chem. Res. 47 (2008) 7419-7423.

[25] M.L. Gray, J.S. Hoffman, D.C. Hreha, D.J. Fauth, S.W. Hedges, K.J. Champagne, H.W. Pennline, Parametric study of solid amine sorbents for the capture of carbon dioxide, Energy Fuels 23 (2009) 4840-4844.

[26] Z. Chen, S. Deng, H. Wei, B. Wang, J. Huang, G. Yu, Polyethylenimine-impregnated resin for high $\mathrm{CO}_{2}$ adsorption: an efficient adsorbent for $\mathrm{CO}_{2}$ capture from simulated flue gas and ambient air, ACS Appl. Mater. Interfaces 5 (2013) 6937-6945. 
[27]S. Sung, M.P. Suh, Highly efficient carbon dioxide capture with a porous organic polymer impregnated with polyethylenimine, J. Mater. Chem. A 2 (2014) $13245-13249$.

[28]S.H. Pang, M.L. Jue, J. Leisen, C.W. Jones, R.P. Lively, PIM-1 as a solution-processable "molecular basket" for $\mathrm{CO}_{2}$ capture from dilute sources, ACS. Macro. Lett. 4 (2015) 1415-1419.

[29]W.J. Son, J.S. Choi, W.S Ahn, Adsorptive removal of carbon dioxide using polyethyleneimine-loaded mesoporous silica materials, Micro. Meso. Mater. 113 (2008) 31-40.

[30]W. Chaikittisilp, H.J. Kim, C.W. Jones, Mesoporous alumina-supported amines as potential steam-stable adsorbents for capturing $\mathrm{CO}_{2}$ from simulated flue gas and ambient air, Energy Fuels 25 (2011) 5528-5537.

[31]Y. Kuwahara, D.Y. Kang, J.R. Copeland, N.A. Brunelli, S.A. Didas, P. Bollini, C. Sievers, T. Kamegawa, H. Yamashita, C.W. Jones, Dramatic enhancement of $\mathrm{CO}_{2}$ uptake by poly(ethyleneimine) using zirconosilicate supports, J. Am. Chem. Soc. 134 (2012) 10757-10760.

[32]D.X. Wang, X.L. Ma, C. Sentorun-Shalaby, C.S. Song, Development of carbon-based "molecular basket" sorbent for $\mathrm{CO}_{2}$ capture, Ind. Eng. Chem. Res. 51 (2012) 3048-3057.

[33]Y. Lin, Q. Yan, C. Kong, L. Chen, Polyethyleneimine incorporated metal-organic frameworks adsorbent for highly selective $\mathrm{CO}_{2}$ capture, Sci. Rep. 3 (2013) $1859-1863$. 
[34]Z.Y. Sui, Y. Cui, J.H. Zhu, B.H. Han, Preparation of three-dimensional graphene oxide-polyethylenimine porous materials as dye and gas adsorbents, ACS Appl. Mater. Interfaces 5 (2013) 9172-9179.

[35]S. Yang, L. Zhan, X. Xu, Y. Wang, L. Ling, X. Feng, Graphene-based porous silica sheets impregnated with polyethyleneimine for superior $\mathrm{CO}_{2}$ capture, Adv. Mater. 25 (2013) 2130-2134.

[36] Y.C. Lin, H. Lin, H.M. Wang, Y.G. Suo, B.H. Li, C.L. Kong, L. Chen, Enhanced selective $\mathrm{CO}_{2}$ adsorption on polyamine/MIL-101(Cr) composites, J. Mater. Chem. A 2 (2014) 14658-14665.

[37]C. Chen, S.S. Kim, W.S. Cho, W.S Ahn, Polyethylenimine-incorporated zeolite $13 \mathrm{X}$ with mesoporosity for post-combustion $\mathrm{CO}_{2}$ capture, Appl. Surf. Sci. 332 (2015) $167-171$

[38]S. Gadipelli, H.A. Patel, Z. Guo, An ultrahigh pore volume drives up the amine stability and cyclic $\mathrm{CO}_{2}$ capacity of a solid-amine@carbon sorbent, Adv. Mater. 27 (2015) 4903-4909.

[39]K. Li, J. Jiang, S. Tian, F. Yan, X. Chen, Polyethyleneimine-nano silica composites: a low-cost and promising adsorbent for $\mathrm{CO}_{2}$ capture, J. Mater. Chem. A 3 (2015) 2166-2175.

[40]M.A. Sakwa-Novak, S. Tan, C.W. Jones, Role of additives in composite PEI/oxide $\mathrm{CO}_{2}$ adsorbents: enhancement in the amine efficiency of supported PEI by PEG in $\mathrm{CO}_{2}$ capture from simulated ambient air, ACS. Appl. Mater. Interfaces 7 (2015) 24748-24759. 
[41] M. Irani, M. Fan, H. Ismail, A. Tuwati, B. Dutcher, A. G. Russell, Modified nanosepiolite as an inexpensive support of tetraethylenepentamine for $\mathrm{CO}_{2}$ sorption, Nano Energy 11 (2015) 235-246.

[42] L. Guo, J. Yang, G. Hu, X. Hu, H. DaCosta, M. Fan, $\mathrm{CO}_{2}$ removal from flue gas with amine-impregnated titanate nanotubes, Nano Energy 25 (2016) 1-8.

[43] A. Heydari-Gorji, Y. Belmabkhout, A. Sayari, Polyethylenimine-impregnated mesoporous silica: effect of amine loading and surface alkyl chains on $\mathrm{CO}_{2}$ adsorption, Langmuir 27 (2011) 12411-12416.

[44] W. Zhang, H. Liu, C. Sun, T. C. Drage, C.E. Snape, Performance of polyethyleneimine-silica adsorbent for post-combustion $\mathrm{CO}_{2}$ capture in a bubbling fluidized bed, Chem. Eng. J. 251 (2014) 293-303.

[45] Y.L. Zhang, J. N. Wang, Y. He, Y. He, B.B. Xu, S. Wei, F.S. Xiao, Solvothermal synthesis of nanoporous polymer chalk for painting suerhydrophobic surfaces, Langmuir 27 (2011) 12585-12590.

[46] Y.L. Zhang, S. Wei, F. Liu, Y. Du, S. Liu, Y. Ji, T. Yokoi, T. Tatsumi, F.S. Xiao, Superhydrophobic nanoporous polymers as efficient adsorbents for organic compounds, Nano Today 4 (2009) 135-142.

[47] M.A. Alkhabbaz, P. Bollini, G.S. Foo, C. Sievers, C.W. Jones, Important roles of enthalpic and entropic contributions to $\mathrm{CO}_{2}$ capture from simulated flue gas and ambient air using mesoporous silica grafter amines, J. Am. Chem. Soc. 136 (2014) 13170-13173. 
[48] C.J. Yoo, L.C. Lee, C.W. Jones, Probing intramolecular versus intermolecular $\mathrm{CO}_{2}$ adsorption on amine-grafted SBA-15, Langmuir 31 (2015) 13350-13360.

[49] F. Rezaei, M.A. Sakwa-Novak, S. Bali, D.M. Duncanson, C.W. Jones, Shaping amine-based solid $\mathrm{CO}_{2}$ adsorbents: effects of pelletization pressure on the physical and chemical properties, Micro. Meso. Mater. 204 (2015) 34-42.

[50]C.F. Cogswell, H. Jiang, J. Ramberger, D. Accetta, R.J. Willey, S. Choi, Effect of pore structure on $\mathrm{CO}_{2}$ adsorption characteristics of aminopolymer impregnated MCM-36, Langmuir 31 (2015) 4534-4541.

[51]D. Ko, H.A. Patel, C.T. Yavuz, Synthesis of nanoporous 1,2,4-oxadiazole networks with high $\mathrm{CO}_{2}$ capture capacity, Chem. Commun. 51 (2015) 2915-2917.

[52] X. Xu, C. Song, J.M. Andresen, B.G. Miller, A.W. Scaroni, Novel polyethylenimine-modified mesoporous molecular sieve of MCM-41 type as high-capacity adsorbent for $\mathrm{CO}_{2}$ capture, Energy Fuels 16 (2002) 1463-1469.

[53]J.C. Hicks, J.H. Drese, D.J. Fauth, M.L. Gray, G. Qi, C.W. Jones, Designing adsorbents for $\mathrm{CO}_{2}$ capture from flue gas-hyperbranched aminosilicas capable of capturing $\mathrm{CO}_{2}$ reversibly, J. Am. Chem. Soc. 130 (2008) 2902-2903.

[54]A.L. Myers, J.M. Prausnitz, Thermodynamics of mixed-gas adsorption, AIChE J. 11 (1965) 121-127.

[55]A. Sayari, A. Heydari-Gorji, Y. Yang, $\mathrm{CO}_{2}$-induced degradation of amine-containing adsorbents: reaction products and pathways, J. Am. Chem. Soc. 134 (2012) 13834-13842. 
[56] W. Li, P. Bollini, S.A. Didas, S. Choi, J.H. Drese, C.W. Jones, Structural changes of silica mesocellular foam supported amine-functionalized $\mathrm{CO}_{2}$ adsorbents upon exposure to steam, ACS Appl. Mater. Interfaces 2 (2010) 3363-3372.

[57] W. Li, S. Choi, J. Drese, M. Hornbostel, G. Krishnan, P. Eisenberger, C. Jones, Steam stripping for regeneration of supported amine-based $\mathrm{CO}_{2}$ adsorbents, ChemSusChem 3 (2010) 899-903.

[58] B. Dutcher, H. Adidharma, M. Radosz, Carbon filter process for flue-gas carbon capture on carbonaceous sorbents: steam-aided vacuum swing adsorption option, Ind. Eng. Chem. Res. 50 (2011) 9696-9703.

[59] B. Dutcher, K. Krutkramelis, H. adidharma, M. Radosz, Carbon filter process for flue-gas carbon capture on carbonaceous sorbents: field tests of steam-aided vacuum swing adsorption, Energy Fuels 26 (2012) 2539-2545.

[60] N.K. Sandhu, D. Pudasainee, P. Sarkar, R. Gupta, Steam regeneration of polyethylenimine-impregnated silica sorbent for postcombustion $\mathrm{CO}_{2}$ capture: a multicyclic study, Ind. Eng. Chem. Res. 55 (2016) 2210-2220.

[61] R. Suri, J. Crittenden, D. Hand, Removal and destruction of organic compounds in water using adsorption, steam regeneration, and photocatalytic oxidation processes, J. Environ. Eng. 125 (1999) 897-905. 
Table 1. Textual properties of PDVB and PEI-PDVB composites

\begin{tabular}{lllll}
\hline Samples & PEI loading (wt.\%) & $\mathrm{S}_{\mathrm{BET}}\left(\mathrm{m}^{2} / \mathrm{g}\right)^{[\mathrm{a}]}$ & $\mathrm{V}_{\mathrm{t}}\left(\mathrm{cm}^{3} / \mathrm{g}\right)^{[\mathrm{b}]}$ & $\mathrm{V}_{\mathrm{m}}\left(\mathrm{cm}^{3} / \mathrm{g}\right)^{[\mathrm{c}]}$ \\
\hline PDVB & 0 & 897 & 2.05 & 0.09 \\
0.29PEI@PDVB & 29.0 & 227 & 0.83 & 0 \\
0.42PEI@PDVB & 42.4 & 77 & 0.45 & 0 \\
0.58PEI@PDVB & 57.7 & 38 & 0.32 & 0 \\
0.70PEI@PDVB & 70.0 & 1 & 0.13 & 0 \\
\hline
\end{tabular}

[a] BET surface area; [b] total pore volume; [c] micropore volume. 

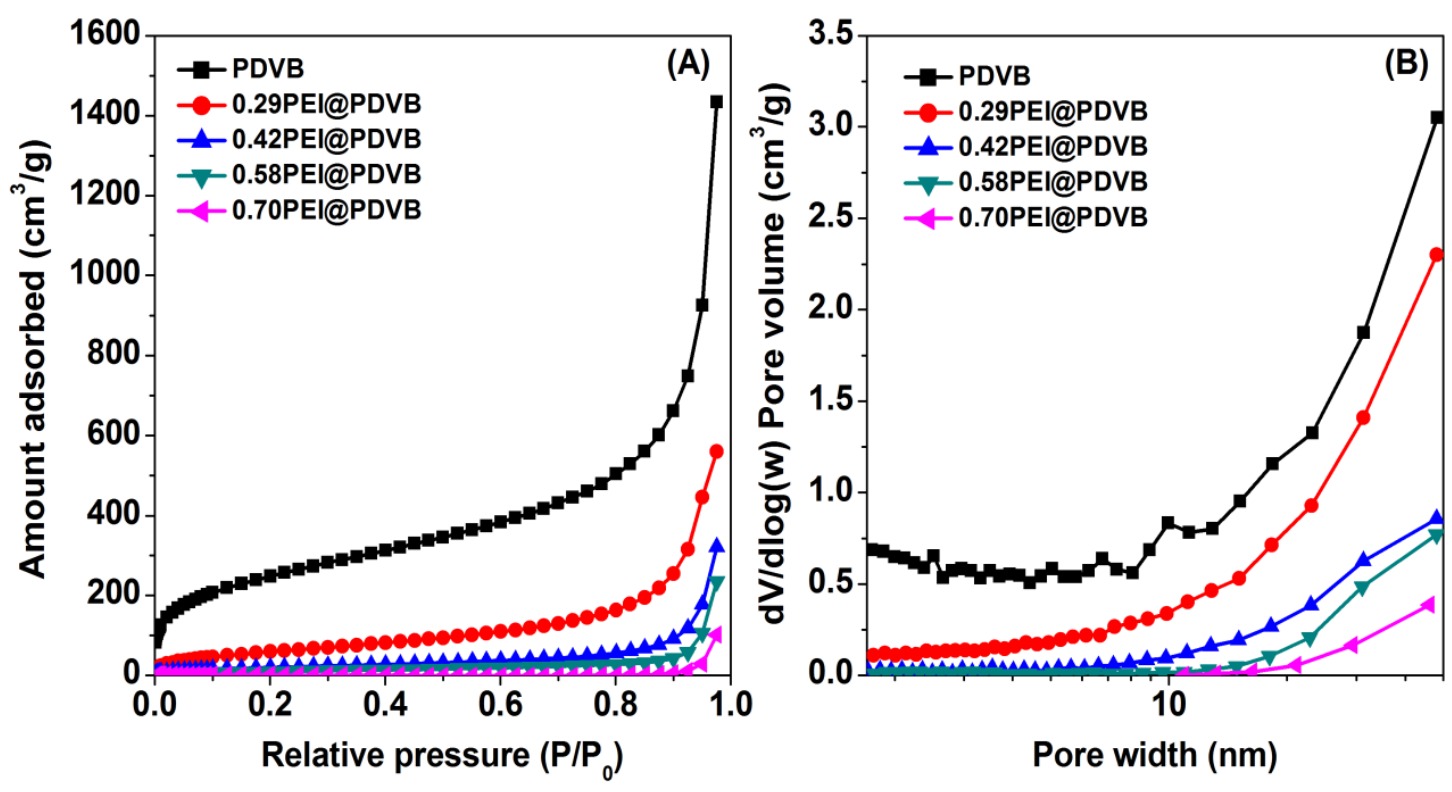

Figure 1. $\mathrm{N}_{2}$ adsorption isotherms at $-196^{\circ} \mathrm{C}$ (A) and pore size distributions (B) of PDVB and PEI-PDVB composites. 


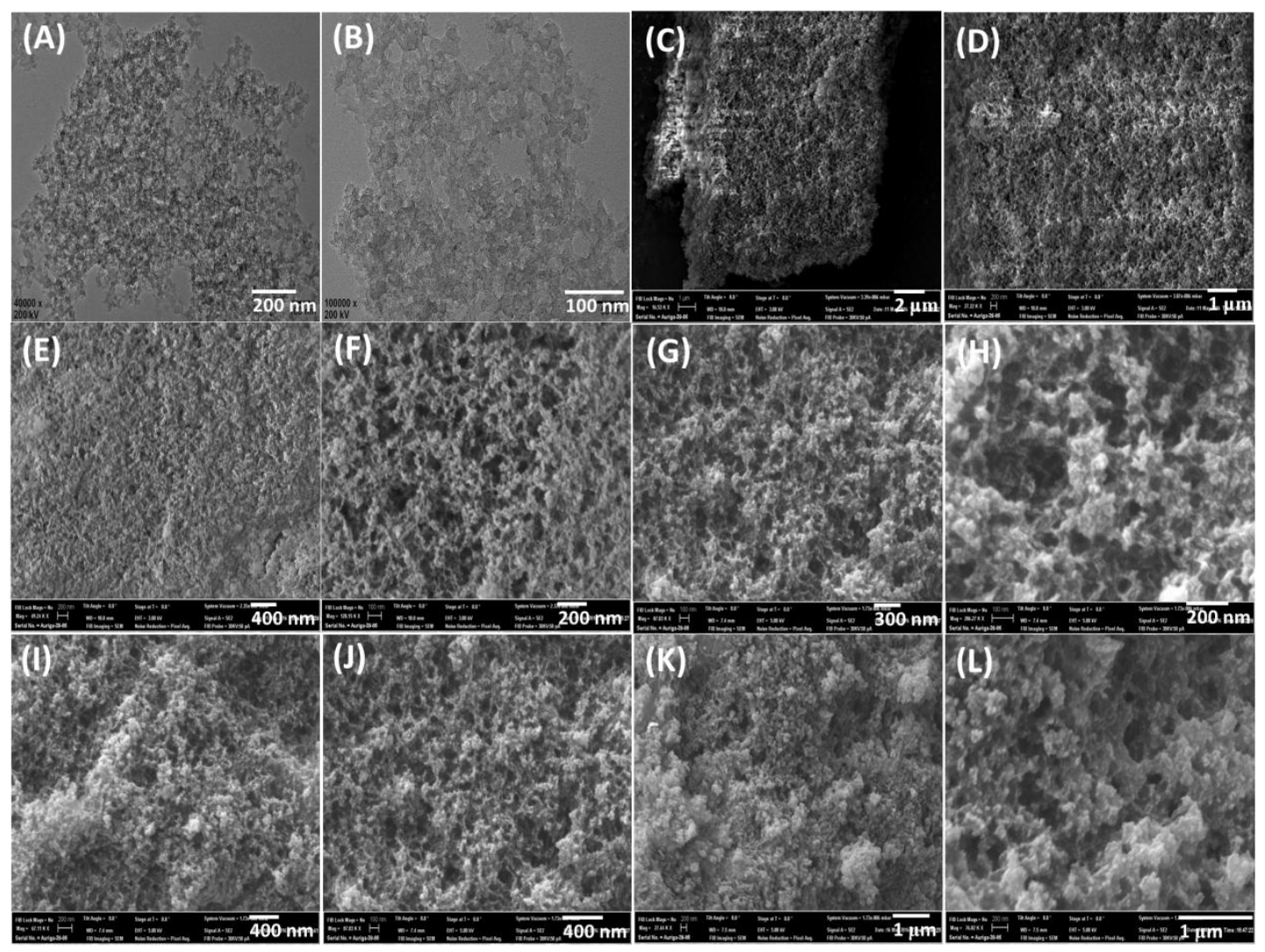

Figure 2. TEM images of PDVB (A, B) and SEM images of PDVB (C, D), 0.29PEI@PDVB (E, F), 0.42PEI@PDVB (G, H), 0.58PEI@PDVB (I, J) and 0.70PEI@PDVB (K, L). 


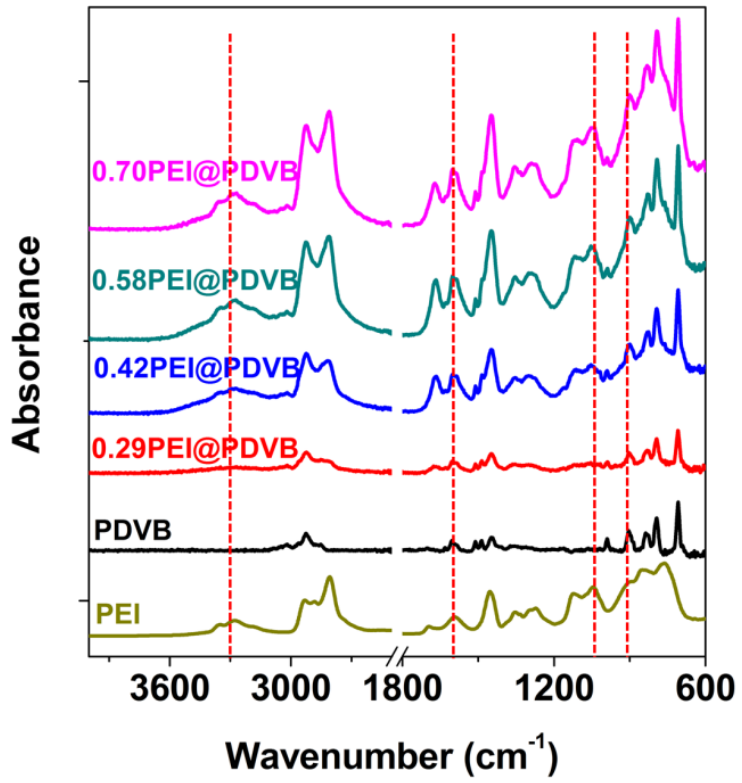

Figure 3. FTIR spectra of PEI, PDVB and PEI@PDVB composites. 

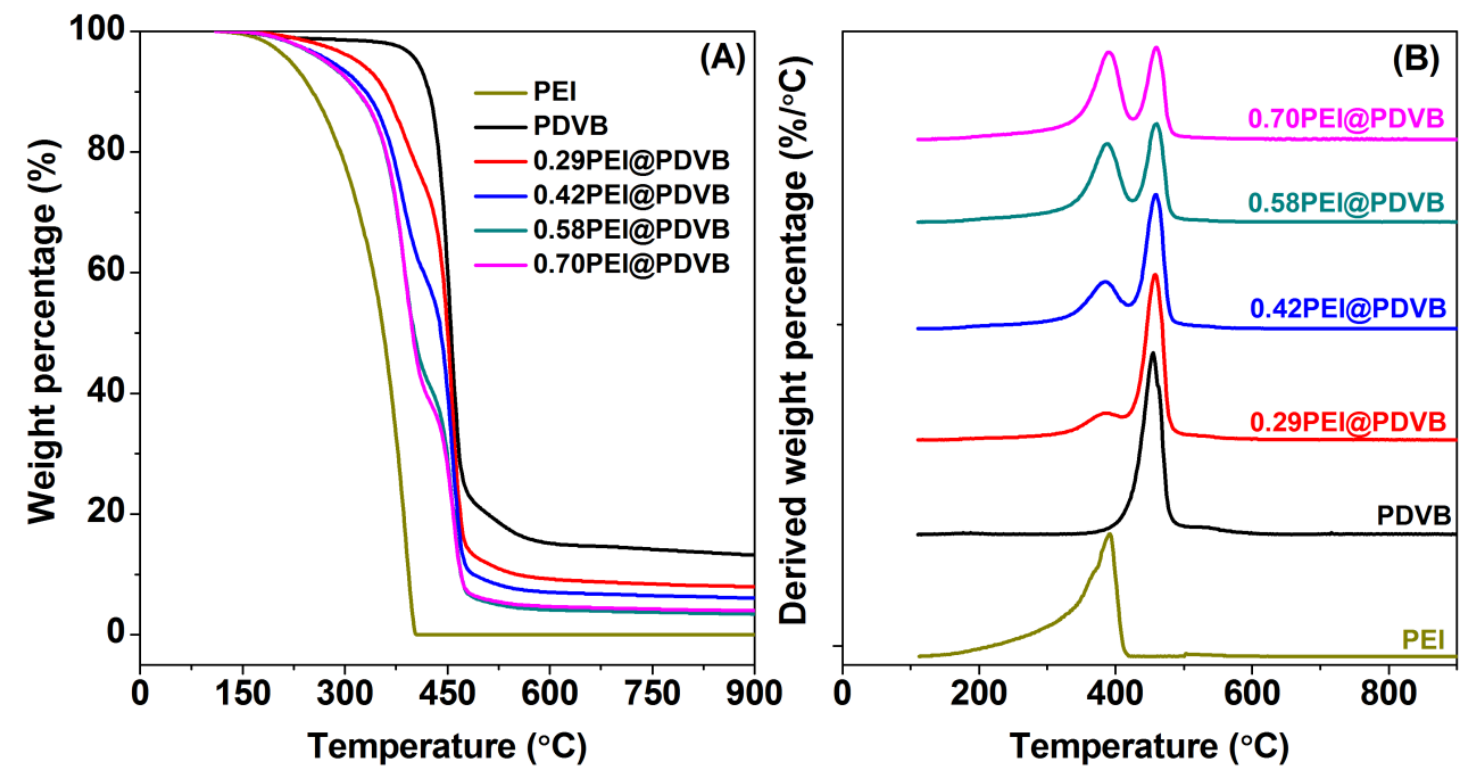

Figure 4. TGA (A) and DTG (B) profiles of PEI, PDVB and PEI-PDVB composites. 

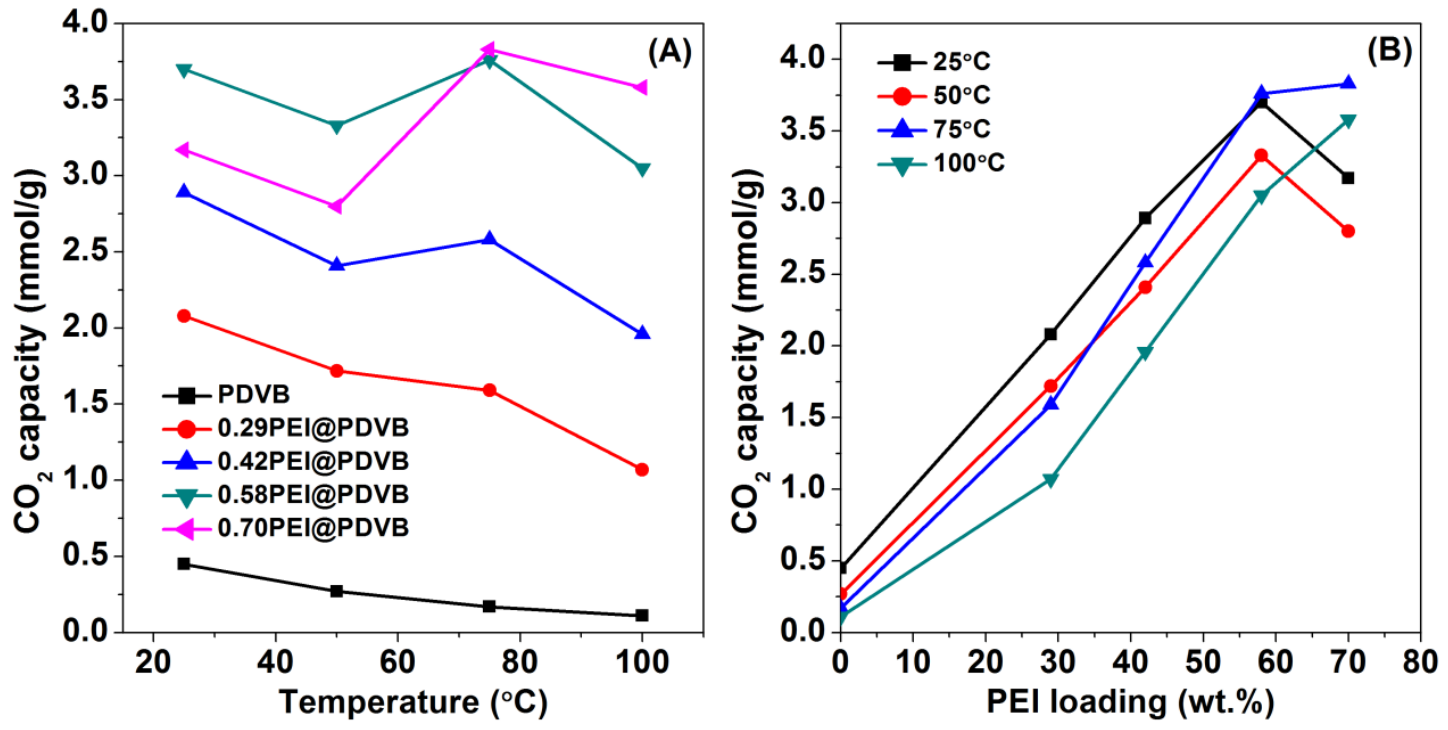

Figure 5. Variation in $\mathrm{CO}_{2}$ capacity with adsorption temperature (A) and PEI loading (B) (adsorption conditions: pure $\mathrm{CO}_{2}, 50 \mathrm{~mL} / \mathrm{min}, 3 \mathrm{~h}$ ). 


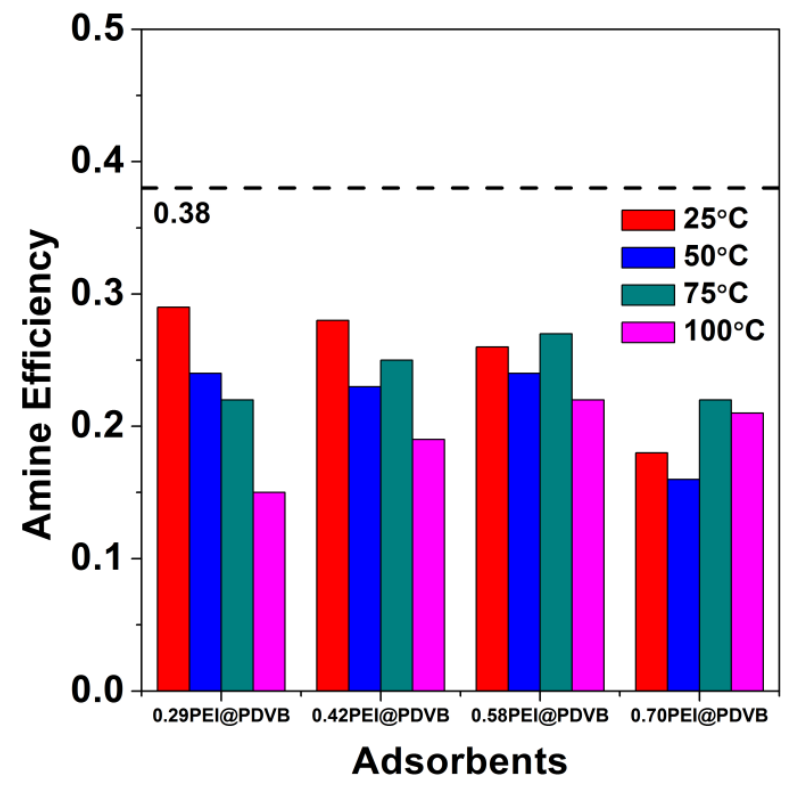

Figure 6. Amine efficiencies of PEI-PDVB composites (adsorption conditions: pure $\mathrm{CO}_{2}, 50 \mathrm{~mL} / \mathrm{min}, 3 \mathrm{~h}$ ). 

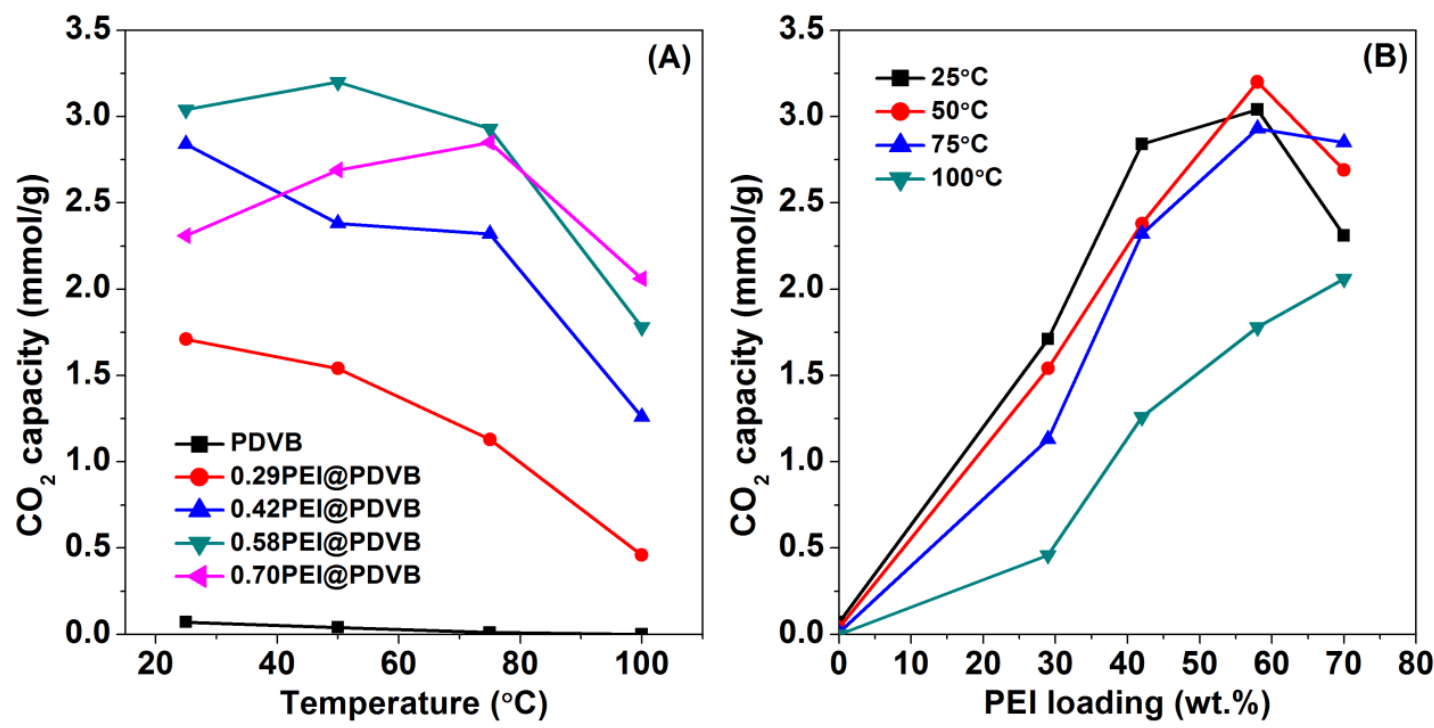

Figure 7. Variation in $\mathrm{CO}_{2}$ capacity with adsorption temperature (A) and PEI loading (B) (adsorption conditions: $15 \% \mathrm{CO}_{2}, 50 \mathrm{~mL} / \mathrm{min}, 3 \mathrm{~h}$ ). 


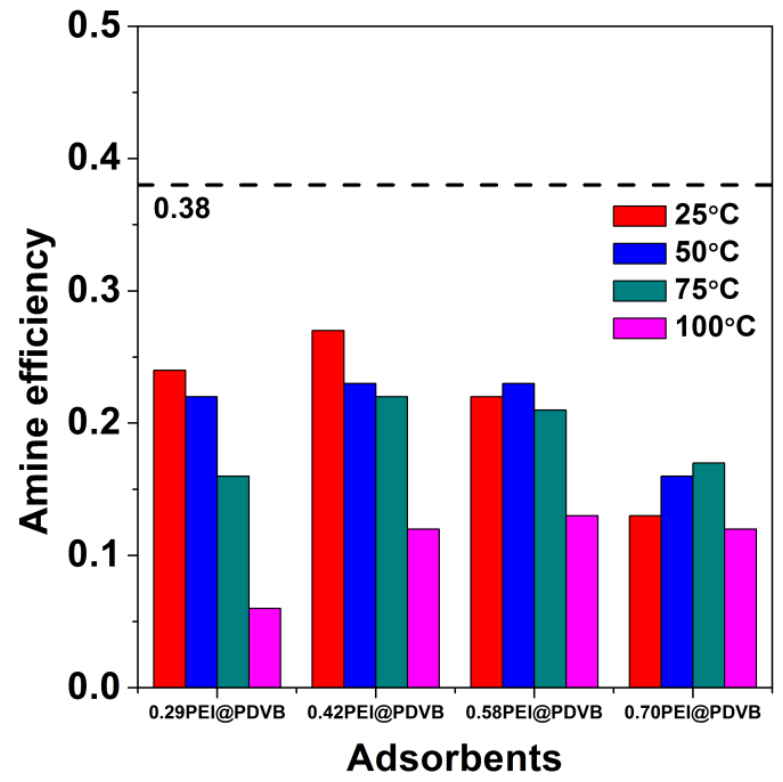

Figure 8. Amine efficiencies of PEI-PDVB composites (adsorption conditions: 15\% $\mathrm{CO}_{2}, 50 \mathrm{~mL} / \mathrm{min}, 3 \mathrm{~h}$ ). 

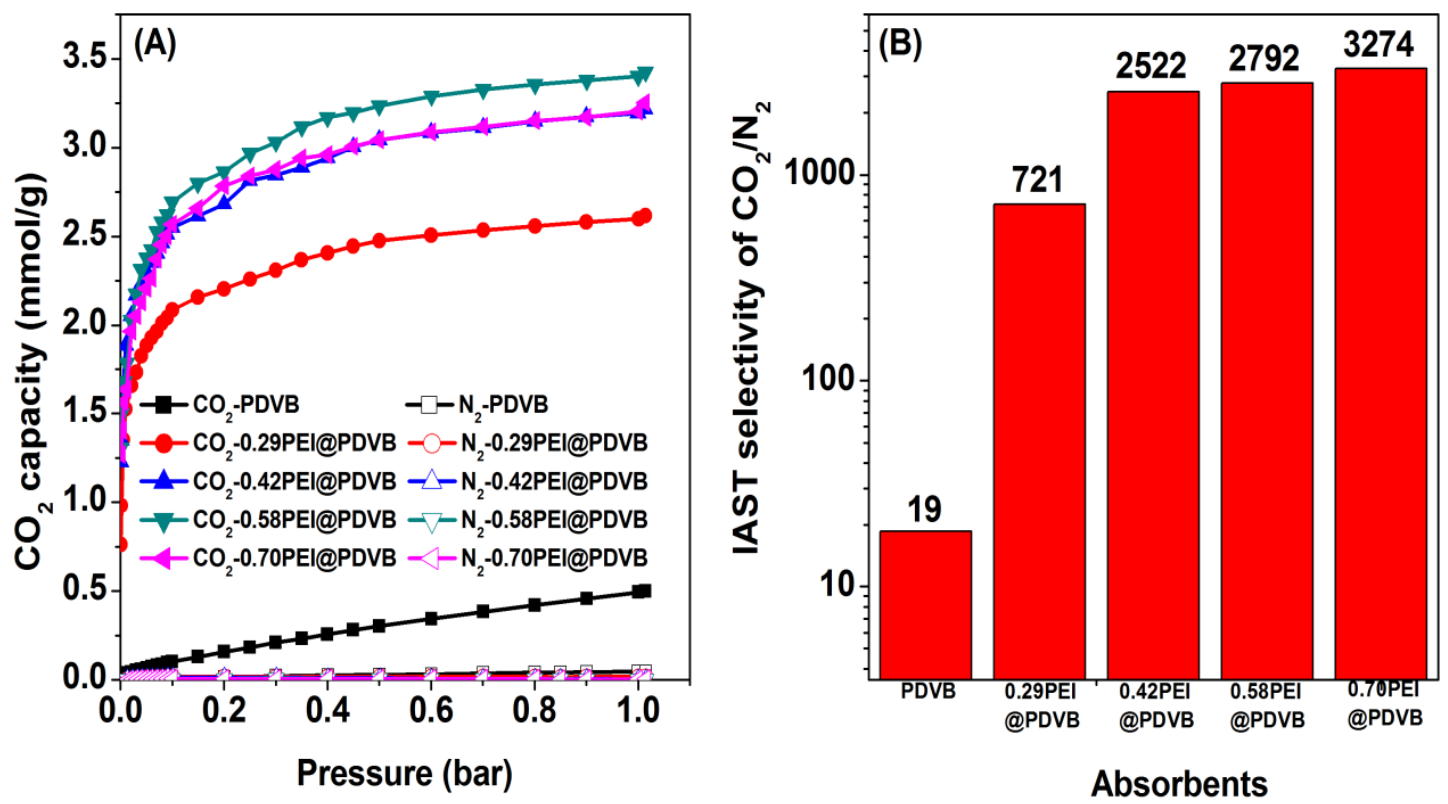

Figure 9. $\mathrm{CO}_{2}$ and $\mathrm{N}_{2}$ adsorption isotherms at $25^{\circ} \mathrm{C}$ (A) and IAST selectivities of $\mathrm{CO}_{2} / \mathrm{N}_{2}(0.15 / 0.85)$ at 1 bar (B) of PDVB and PEI-PDVB composites. 


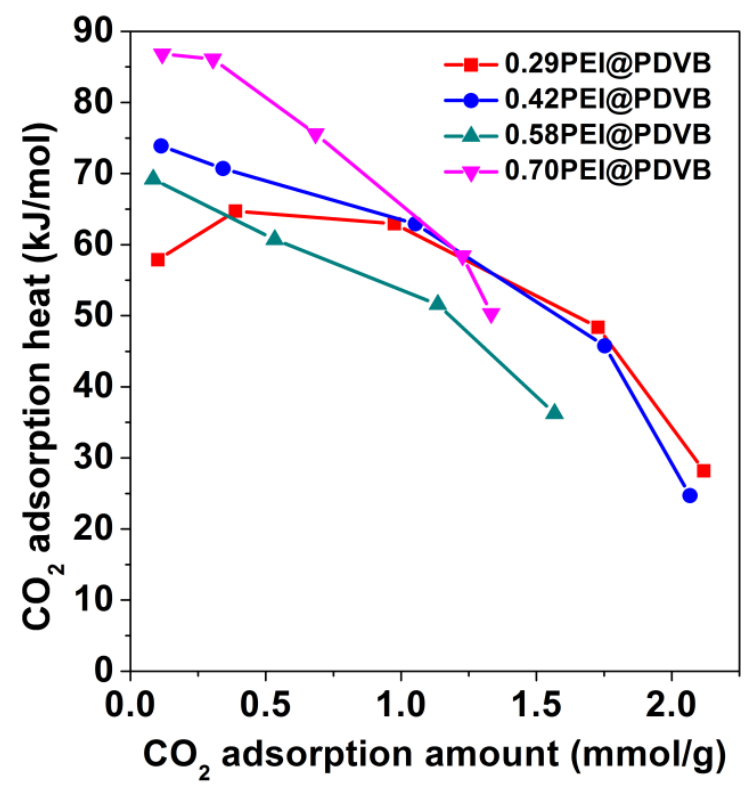

Figure 10. Isosteric heats of $\mathrm{CO}_{2}$ adsorption on PEI-PDVB composites as a function of $\mathrm{CO}_{2}$ uptake measured by the calorimetric method. 


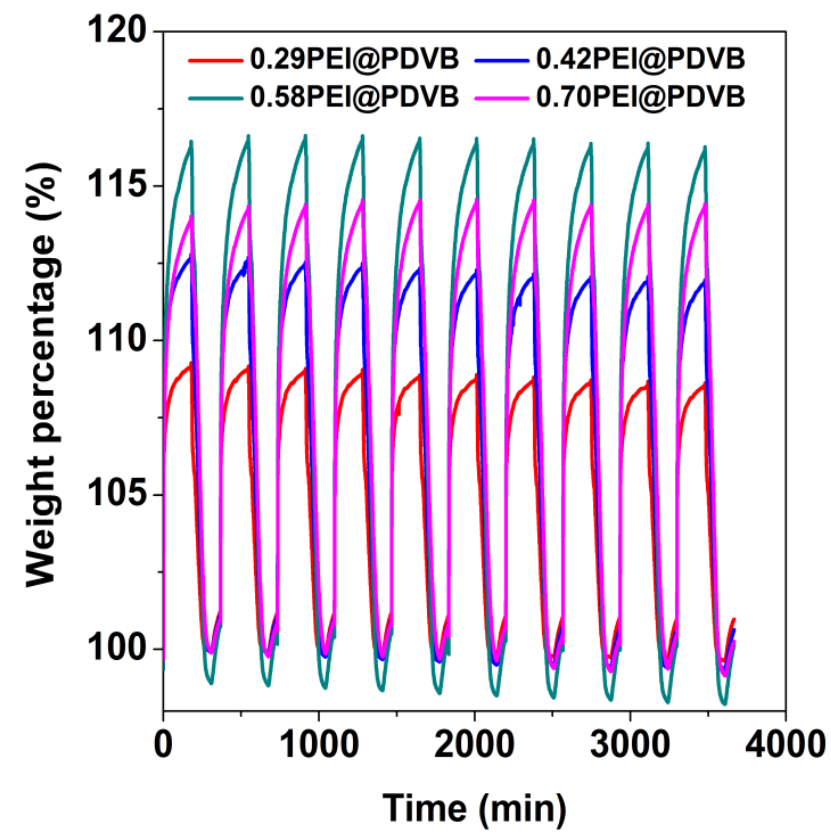

Figure 11. Cycling of $\mathrm{CO}_{2}$ adsorption on PEI-PDVB composites under dry conditions (adsorption conditions: pure $\mathrm{CO}_{2}, 25^{\circ} \mathrm{C}, 50 \mathrm{~mL} / \mathrm{min}, 180 \mathrm{~min}$; desorption conditions: pure $\mathrm{N}_{2}, 75^{\circ} \mathrm{C}, 150 \mathrm{~mL} / \mathrm{min}, 120 \mathrm{~min}$ ). 


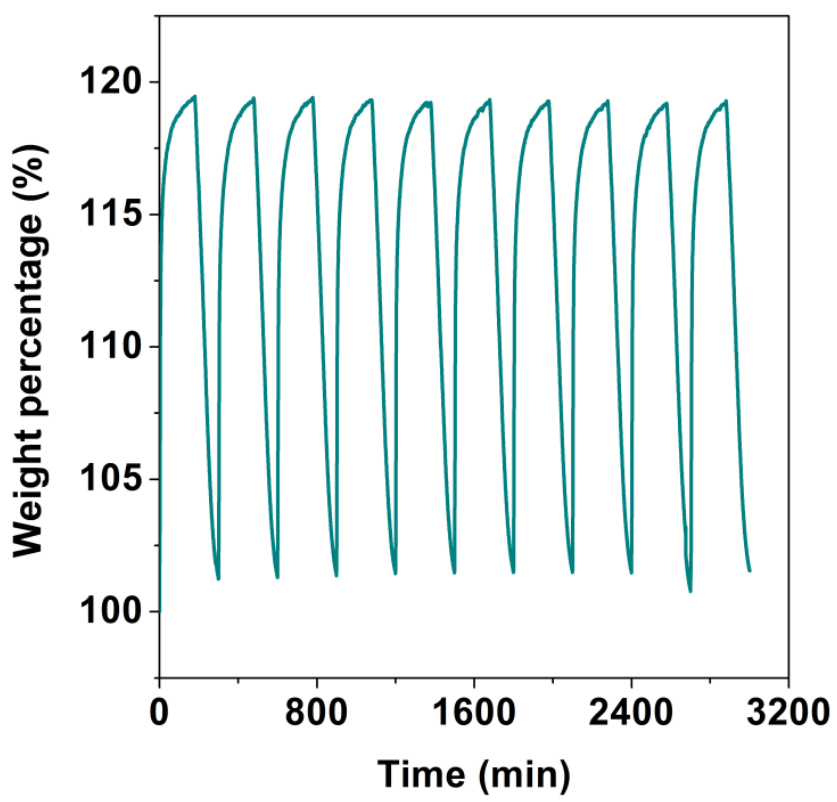

Figure 12. Cycling of $\mathrm{CO}_{2}$ adsorption on PEI-PDVB composites under humidified conditions (adsorption conditions: $\mathrm{CO}_{2}$ with $10 \%$ relative humidity, $75^{\circ} \mathrm{C}, 50 \mathrm{~mL} / \mathrm{min}$, $180 \mathrm{~min}$; desorption conditions: pure $\mathrm{N}_{2}, 75^{\circ} \mathrm{C}, 150 \mathrm{~mL} / \mathrm{min}, 120 \mathrm{~min}$ ). 
Graphical Abstract

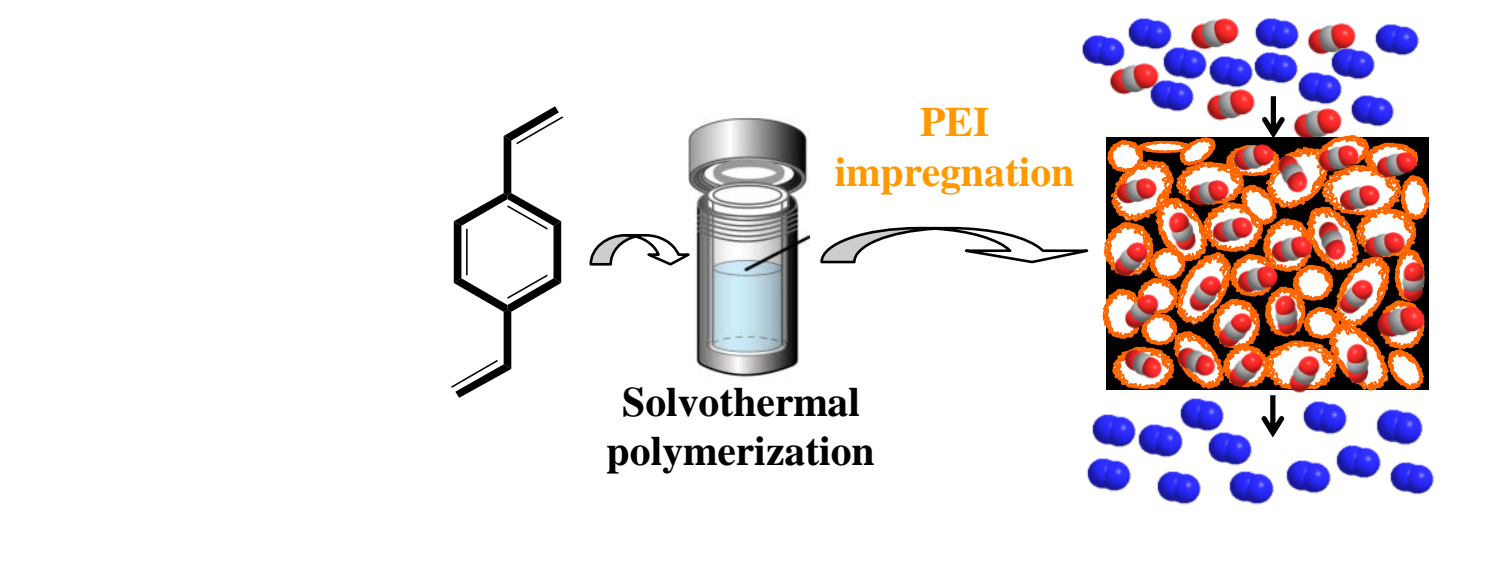

Solvothermal polymerization

.0000

\section{Graphical Abstract}

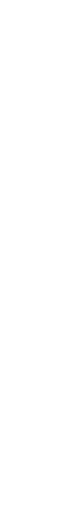

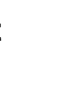

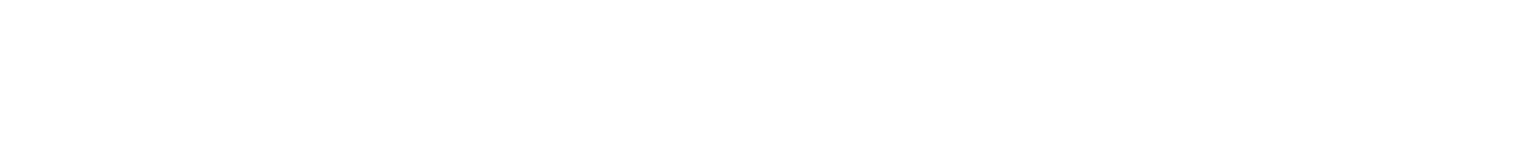

